\title{
Functional Annotation, Genome Organization and Phylogeny of the Grapevine (Vitis vinifera) Terpene Synthase Gene Family Based on Genome Assembly, FLcDNA Cloning, and Enzyme Assays
}

Diane M Martin ${ }^{1,2 \dagger}$, Sébastien Aubourg ${ }^{3 \dagger}$, Marina B Schouwey ${ }^{4}$, Laurent Daviet ${ }^{4}$, Michel Schalk ${ }^{4}$, Omid Toub ${ }^{1,2}$, Steven T Lund², Jörg Bohlmann ${ }^{1 *}$

\begin{abstract}
Background: Terpenoids are among the most important constituents of grape flavour and wine bouquet, and serve as useful metabolite markers in viticulture and enology. Based on the initial 8-fold sequencing of a nearly homozygous Pinot noir inbred line, 89 putative terpenoid synthase genes (VVTPS) were predicted by in silico analysis of the grapevine (Vitis vinifera) genome assembly [1]. The finding of this very large VVTPS family, combined with the importance of terpenoid metabolism for the organoleptic properties of grapevine berries and finished wines, prompted a detailed examination of this gene family at the genomic level as well as an investigation into VVTPS biochemical functions.
\end{abstract}

Results: We present findings from the analysis of the up-dated 12-fold sequencing and assembly of the grapevine genome that place the number of predicted VVTPS genes at 69 putatively functional VVTPS, 20 partial VVTPS, and 63 VVTPS probable pseudogenes. Gene discovery and annotation included information about gene architecture and chromosomal location. A dense cluster of 45 VVTPS is localized on chromosome 18. Extensive FLcDNA cloning, gene synthesis, and protein expression enabled functional characterization of $39 \mathrm{VVTPS}$; this is the largest number of functionally characterized TPS for any species reported to date. Of these enzymes, 23 have unique functions and/or phylogenetic locations within the plant TPS gene family. Phylogenetic analyses of the TPS gene family showed that while most VVTPS form species-specific gene clusters, there are several examples of gene orthology with TPS of other plant species, representing perhaps more ancient VVTPS, which have maintained functions independent of speciation.

Conclusions: The highly expanded VVTPS gene family underpins the prominence of terpenoid metabolism in grapevine. We provide a detailed experimental functional annotation of 39 members of this important gene family in grapevine and comprehensive information about gene structure and phylogeny for the entire currently known VVTPS gene family.

\section{Background}

Terpenoids are a large class of metabolites that are involved in the fragrance and aroma constituents of flowers and fruits, plant defense, and primary plant metabolism [2-4]. Although all terpenoids arise from a

\footnotetext{
* Correspondence: bohlmann@msl.ubc.ca

† Contributed equally

'Michael Smith Laboratories, University of British Columbia, 2185 East Mall,

Vancouver, B.C, V6T 1Z4, Canada

Full list of author information is available at the end of the article
}

few structurally simple prenyldiphosphate precursors, an enormous assortment of thousands of possible molecules comes to fruition. This chemical diversity of terpenoid structures is attributed, in large part, to the myriad ways of folding and the eventual quenching of reactive carbocation intermediates in the reaction catalyzed by terpenoid synthases (TPS) $[5,6]$. The products of TPS can be further modified by other enzymes such a cytochrome P450 dependent monooxygenases and various transferases. 
The initial 8-fold sequencing and assembly of a grapevine (Vitis vinifera L.) inbred Pinot noir genome (PN40024) lead to the prediction of 89 grapevine TPS ( $V v T P S)$ genes, which mirrors a vibrant role for terpenoid secondary metabolism in grapevine biology $[7,8]$. For example, in wine made from aromatic grape varieties, monoterpene alcohols such as linalool, geraniol, and cis-rose oxide impart important floral flavour qualities [9]. Sesquiterpenes have also been identified as important indicators of grape aroma. Recently, Parker et al. [10] identified $\alpha$-ylangene as a sesquiterpene metabolite marker associated with peppery aroma and taste in Australian Shiraz grape berries, and the sesquiterpene ketone, rotundone, was found to be the compound responsible for this attribute in peppery/spicy Australian Shiraz grapes and wines [11]. Monoterpenes such as 1,8 -cineol, and sesquiterpenes such as $\alpha$-humulene, $\beta$-caryophyllene as wells as $\alpha$ - and $\gamma$-muurolene have been described in Cabernet Sauvignon pre-veraison berries [12]. Similar profiles of terpene volatiles have also been documented from the headspace above Chardonnay leaves, flowers, and green berries [13]. The presence of some terpenes early in berry development and in other parts of the plant may indicate a role in defense. Terpenoid volatiles are released from grapevines following insect feeding [14] or the application of methyl jasmonate [15].

Of all plant species for which genome sequences are available, the TPS gene family has been comprehensively explored only in Arabidopsis thaliana, in which 32 intact AtTPS genes were identified [16]; functions have been established for several of these genes [17-20]. A number of TPS genes have also been characterized against the background of the sequenced rice (Oryza sativa) genome [21-26] which has at least 40 TPS-like sequences identified ( $\mathrm{S}$. Aubourg unpublished results). For comparison, genome sequence analysis of poplar (Populus trichocarpa) identified 47 TPS genes [27], only two of which have been functionally characterized $[28,29]$. Prior to the sequencing of a grapevine genome, we reported on the cDNA cloning and product profiles of three $\operatorname{VvTPS}[30,31]$ and we detailed the involvement of valencene synthase, a sesquiterpene synthase, in the evolution of grapevine floral scent [32], but a comprehensive analysis of $V v T P S$ has not been reported thus far.

The importance of terpenoids in grapevine biology and wine flavour and quality motivated a genome-wide inventory and functional characterization of the $V \nu T P S$ gene family. We present the manually curated annotation of the $V v T P S$ gene family from the current 12 -fold genome sequence coverage. This work defines 69 putatively functional $V v T P S, 20$ partial $V v T P S$, and 63 probable $V v T P S$ pseudogenes including $V v T P S$ gene architecture and chromosome localizations. The $V v T P S$ gene family shows extensive gene duplication and in many instances, functional diversification across all subfamilies except those involved in primary metabolism (subfamilies TPS-c and $T P S-e)$. Conclusions regarding diversification are supported by phylogenetic analyses of the VvTPS family and functional characterization of heterologously expressed VvTPS proteins.

\section{Results and Discussion}

\section{Genome-wide identification of TPS genes in Vitis vinifera}

Screening of the predicted proteome and the six-framestranslated 12-fold genome sequence of $V$. vinifera with protein sequences of previously characterized TPS identified 152 loci exhibiting significant similarities with known TPS (see the Methods section for details). Our annotation of the 152 TPS-like gene models (Additional File 1) classified them into four types: (i) 53 are complete $V v T P S$ genes that contain the expected functional motifs and domains $[16,33,34]$ required to render them functional; (ii) 16 are complete $V v T P S$ genes but the ORFs contain a frameshift or premature stop codon either due to a point mutation or a possible sequencing error; (iii) 20 are partial TPS genes disrupted by sequence gaps or located in scaffold extremities; and (iv) 63 are obvious pseudogenes disrupted by numerous deletions, frameshifts and/or stop codons (Additional File 1). After removing the genes of this last type, the number of potentially functional $V v T P S$ ranges from a minimum of 53 up to 89 genes. The missing sequences of the partial genes (group iii) prevented meaningful sequence alignments and gene classification; therefore, we removed them from our further analysis which focused on the $69 V v T P S$ genes of groups (i) and (ii). The presence of cognate EST and/or cDNA sequences provides proof of transcription for 40 (58\%) of them (Additional File 1).

The relatively high gene sequence and structure conservation across the plant TPS family [16] allow us to be confident in the result of the genome-wide $V v T P S$ gene prediction, combining automatic and manual annotations. Manual curation and evaluation have substantially improved the identification of $V v T P S$ genes: For example, out of the $69 V v T P S$ genes 12 were missed by the automated pipeline used for annotation of the grapevine genome [1,35]. Furthermore, intron-exon structures of $40 V v T P S$ genes required manual correction to obtain complete and consistent coding sequences. The results of the $V v T P S$ gene annotations confirmed a large $V v T P S$ gene family previously predicted from the 8 -fold genome assembly [1] and expand the previous estimation of the $V v T P S$ family size. While a lower estimate of only 35 $V \nu T P S$ genes was reported from the analysis of a second heterozygous Pinot noir genome sequence [36], the 
sequence information available for this genome in NCBI GenBank http://www.ncbi.nlm.nih.gov/genbank also revealed about $70 V v T P S$. A comparison with other plant genomes in which TPS genes have been annotated showed that the grapevine VvTPS gene family is the largest identified to date. The Arabidopsis thaliana genome contains 32 complete AtTPS genes and eight AtTPS pseudogenes [16], while the rice and poplar genomes are predicted to encode 40 to 50 TPS-like genes according to [27] and unpublished results (S. Aubourg).

\section{Annotation of VvTPS relative to the overall plant TPS gene family}

The 69 candidate $V v T P S$ sequences identified as intact or potentially intact represent five of the seven plant $T P S$ gene subfamilies TPS- $a$ through TPS- $g$ previously described [16,33,37] (Figure 1; Additional File 1). The $T P S$ - $f$ subfamily of Clarkia brewerii linalool synthaselike genes and the gymnosperm-specific TPS- $d$ subfamily [33], were the only subfamilies missing full-length $V v T P S$ members. Although the previous 8-fold grapevine genome assembly [1] contained one VvTPS-f subfamily member, in the manually curated assembly and annotation of the 12-fold genome sequence, this gene was now fragmented into two partial TPS (Additional File 1).

The TPS- $a$ subfamily is substantially extended in grapevine with $30 V v T P S$ existing on just two chromosomes, chromosomes 18 and 19, compared to 22 AtTPS of the TPS- $a$ subfamily in A. thaliana [16]. This subfamily typically contains sesquiterpene synthases and possibly diterpene synthases of secondary metabolism. A total of $19 V v T P S$ were found in the TPS- $b$ subfamily of angiosperm monoterpene synthases and these were located on at least three chromosomes, chromosomes 8, 12 and 13. The TPS- $g$ subfamily, which contains synthases for acyclic monoterpenes of floral scent [37] is greatly extended in grapevine with $17 V v T P S$ annotated compared to Arabidopsis with just one AtTPS gene in this subfamily. The chromosomal location of most of the $V V T P S$ of the TPS-g subfamily is unknown. We found two VVTPS of the TPS-c subfamily and one $V \nu T P S$ of the TPS-e subfamily. These two subfamilies contain TPS genes of primary plant hormone metabolism that are not typically represented with multiple gene copies in plant genomes [16,33,38].

\section{Chromosomal location of VvTPS}

The topological organization of the $V v T P S$ family in the grapevine genome is characterized by massively tandemly repeated genes. Of the complete set of 152 VvTPS loci identified in this study, 129 (85\%) are organized in 13 distinct clusters covering from 2 to 45 $V \nu T P S$ genes or pseudogenes (Additional File 1). The largest $V v T P S$ cluster, localized on chromosome 18 and spanning $690 \mathrm{~kb}$, contains 20 complete $V v T P S$ genes (all are members of the TPS- $a$ subfamily), $25 V v T P S$ pseudogenes and numerous traces of Copia-like retrotransposons (Figure 2). Although many $V v T P S$ cluster together, of the $152 V v T P S$ loci, only $2 V v T P S$ genes also localize in the vicinity of other putative terpenoid pathway genes with the same gene orientation: one (VvTPS42) co-localizes with a prenyltranferase gene and the other (the pseudogene GSVIVT01014893001) with a cytochrome P450 gene. Dynamically expanding or contracting clusters of closely related genes can evolve as the result of unequal cross-over, which enriches genetic variability but limits the divergence through an opposing mechanism of gene conversion as has been shown for plant resistance genes $[39,40]$. These processes can be intensified by the presence of pseudogenes which contribute to the frequency of crossing-over and increase in gene diversity [41]. As previously shown for the Drosophila melanogaster genome, a high density of repeat elements can also impact the recombination dynamic within gene clusters [42]. The genome architecture of the $V v T P S$ gene family (i.e., the number, size and nature of $V v T P S$ clusters in the grapevine genome) suggests a large potential for diversification and variation of terpenoid metabolism in this species, and may thus account for variability of terpenoid profiles among grapevine varieties and cultivars. The identification of $V v T P S$ gene clusters allows for future work in which resequencing of these regions in different varieties and testing for associations of gene cluster and terpenoid aroma traits can be undertaken.

\section{Intron-exon structure of VvTPS genes}

In agreement with highly conserved intron-exon structure of plant TPS genes $[16,43,44]$, all but one of the 66 $V v T P S$ genes of the subfamilies TPS- $a$, TPS- $b$ and TPS- $g$ contain seven coding exons (Figure 3 ). The only exception is VvTPS17 (TPS- $a$ ) in which the 3'-most exon was disrupted by a large and probably recent intron insertion. The three genes of the subfamilies TPS-c and TPS- $e$ are characterized by longer sequences (15 and 13 exons respectively) as a consequence of the presence of an additional exon encoding an ancestral 200 amino acid N-terminal domain of unknown function $[16,33,38]$.

\section{Conserved motifs of the $V$. vinifera TPS protein family}

The grapevine VvTPS protein family is characterized by two large domains defined in the PFAM resource [45]: PF01397 corresponds to the $\mathrm{N}$-terminal region and PF03936 corresponds to the C-terminal metal cofactor binding domain [46]. Just upstream of the PF01397 Nterminal domain, in the region encoded by the first exon, all VvTPS that putatively function as monoterpene 


\section{Chromosome Location}
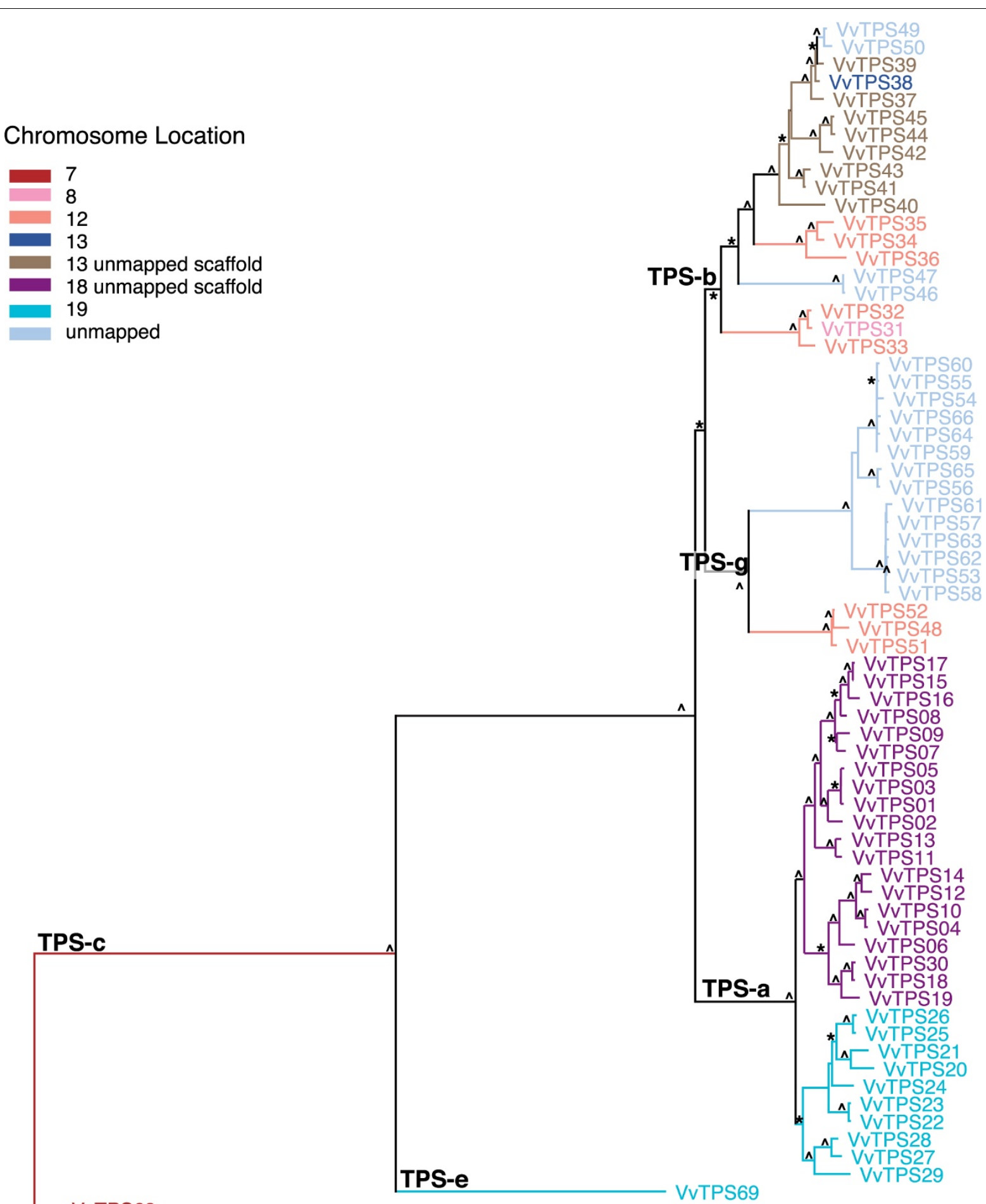

\section{1 substitutions per site}

Figure 1 Phylogeny and chromosome location of 69 putative intact VvTPS identified as gene models in the 12-fold coverage genome sequence assembly of Vitis vinifera (Pinot noir). Maximum likelihood analysis of the $V$. vinifera VVTPS gene family. Bootstrap values supported by $\geq 50 \%$ are designated ${ }^{*}$ and those with values $\geq 80 \%$ are indicated with $\wedge$. Colors indicate chromosome location known at this time. Light blue $=$ unmapped scaffold, brown $=$ chromosome 13 (unmapped scaffold), dark blue $=$ chromosome 13 , orange $=$ chromosome 12 , pink $=$ chromosome 8, purple $=$ chromosome 18 (unmapped scaffold), teal $=$ chromosome 19, and red = chromosome 7. 

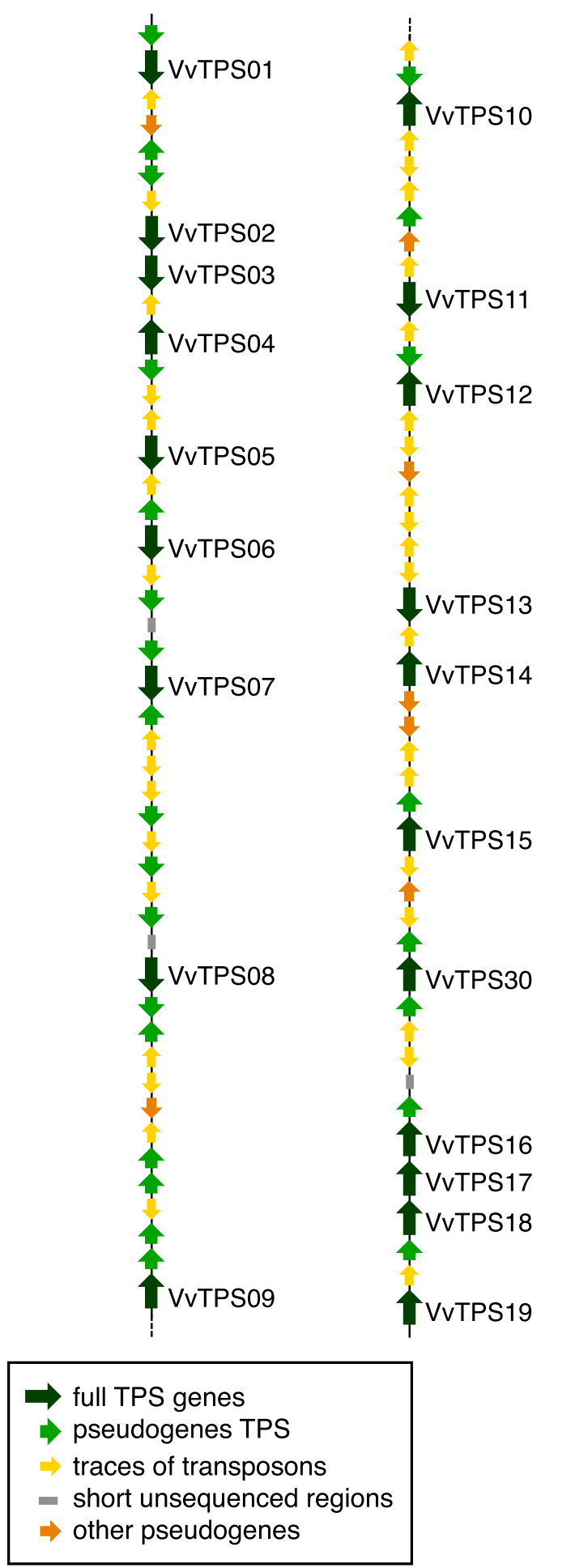

Figure 2 Genomic organization of a $\mathbf{6 9 0}$ kb multi-gene VvTPS cluster. A $690 \mathrm{~kb}$ long genomic region of chromosome 18 contains a large cluster of 20 complete VVTPS-a genes (dark green arrows), 25 pseudo-TPS- $a$ genes characterized by several deletions,

frameshifts and/or stop codons (light green arrows), few traces of other genes (orange arrows) and numerous vestiges of the Copialike transposable element (yellow arrows). synthases, also contain the $\mathrm{RR}(\mathrm{x})_{8} \mathrm{~W}$ motif. This motif may play a role in the initiation of the isomerizationcyclization reaction [47] or act to stabilize the protein through electrostatic interactions [48]; however, TPS in subfamily TPS-g, as well as two VvTPS predicted in TPS- $a$, and those in TPS- $c$ and TPS-e do not consistently contain this motif or they have a highly modified version of it (Figure 3 and 4A). Several of the TPS-g members are also truncated with the starting $M$ at position five of this motif. This may effectively open up the three dimensional structure of these TPS or it may affect subcellular compartmentation of these proteins. Mono- and diterpene synthases typically contain an Nterminal plastidial targeting peptide upstream of the conserved or modified $\mathrm{RR}(\mathrm{x})_{8} \mathrm{~W}$ [33], and such targeting peptides have been predicted in silico for 21 VvTPS (Figure 3).

The C-terminal domain contains two highly conserved aspartate-rich motifs. The first of these, the DDxxD motif (Figure 3), is involved in the coordination of divalent ion(s), water molecules and the stabilization of the active site $[46,49,50]$. Only four predicted VvTPS (VvTPS48, VvTPS66 and the two TPS-c proteins VvTPS67 and VvTPS68) lack the exact DDxxD motif characteristic of class I TPS which catalyze reactions initiated by cleavage of the diphosphate group of the prenyl diphosphate substrate. The TPS-c proteins are not expected to have this domain as they do not cleave the prenyl diphosphate unit; however, they do contain the DXDD sequence critical to the protonation initiated reaction mechanism of class II TPS [51].

A second important motif in the C-terminal domain is the NSE/DTE motif [52,53]. The reported consensus sequence of this motif is $(\mathrm{L}, \mathrm{V})(\mathrm{V}, \mathrm{L}, \mathrm{A})(\mathrm{N}, \mathrm{D}) \mathrm{D}(\mathrm{L}, \mathrm{I}, \mathrm{V}) \mathrm{x}(\mathrm{S}$, T) $x x x E$ and a modified version, $(\mathrm{L}, \mathrm{F})(\mathrm{M}, \mathrm{I}, \mathrm{S}, \mathrm{C}, \mathrm{W})(\mathrm{N}, \mathrm{D}) \mathrm{D}$ $(\mathrm{L}, \mathrm{M}, \mathrm{I}) \mathrm{x}(\mathrm{S}, \mathrm{T}, \mathrm{D}) \mathrm{xxxE}$, is found in almost all VvTPS of the subfamilies TPS- $a,-b$, and $-g$ (Figure 4B). Three predicted VvTPS are lacking the terminal E. Members of the TPS-g subfamily have an altered and highly conserved sequence, LWDDLx(S,T) xxxE.

\section{Functional characterization of VvTPS full length CDNAs}

Since specific functions of TPS genes cannot be accurately predicted from sequence analysis alone, it was important to clone and functionally characterize $V v T P S$ full length (FL)cDNAs. We used the previously published 8-fold [1] and the new 12-fold genome sequence (GenBank, NCBI project ID 18785) assembly of the Pinot noir inbred line for primer design to clone VvTPS FLcDNAs from three grapevine varieties, Pinot noir (PN), Cabernet Sauvignon (CS), and Gewürztraminer (Gw). FLcDNAs were expressed in E. coli using one of several cloning vectors (see Materials and Methods), and recombinant VvTPS proteins were functionally 


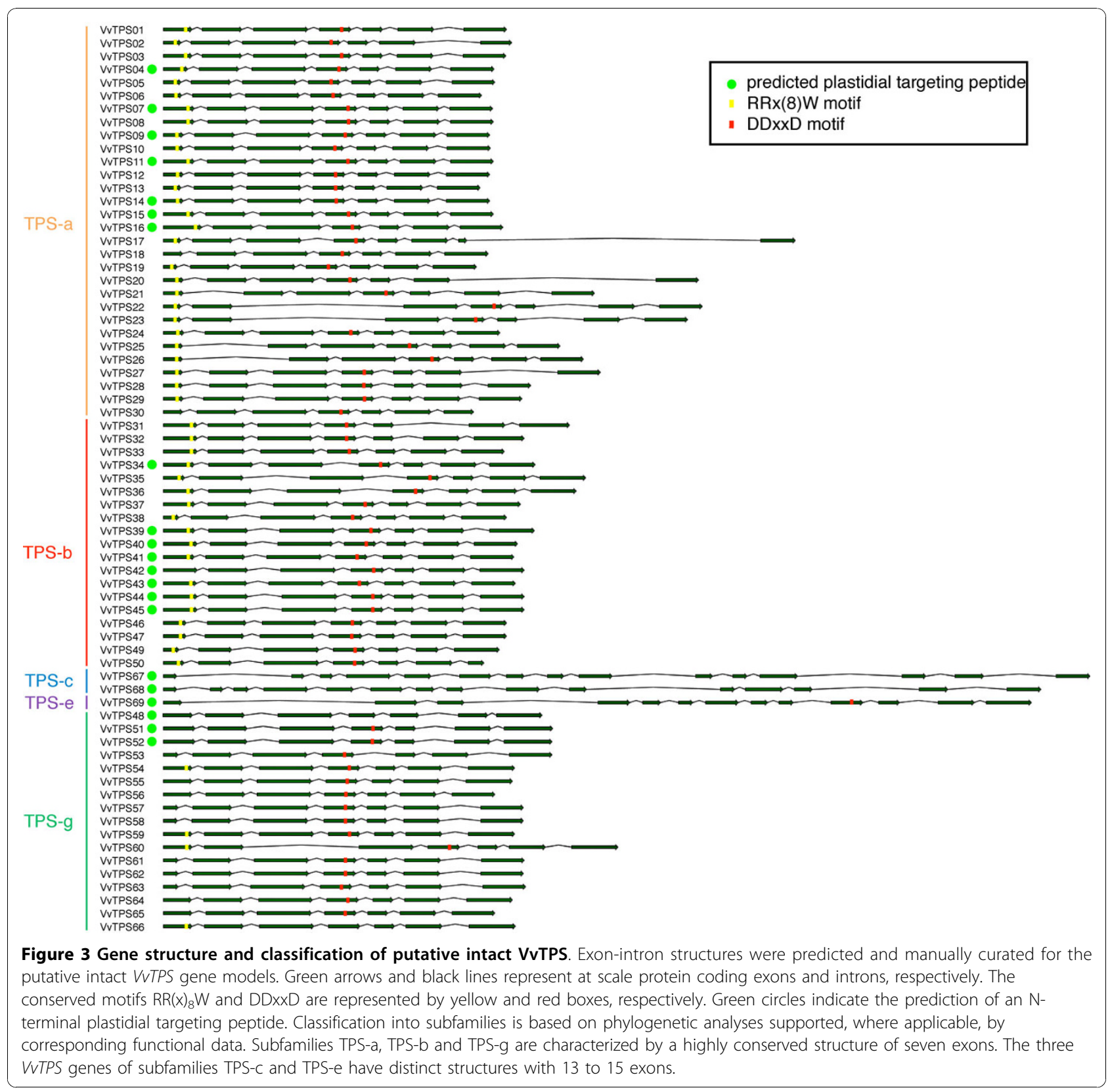

characterized via purified protein or in vivo recombinant $E$. coli assays with each of the following potential substrates, geranyl diphosphate (C10, GPP), (E,E)-farnesyl diphosphate (C15, FPP), and $(E, E, E)$-geranylgeranyl diphosphate (C20, GGPP). Although a couple of recent studies identified two tomato TPS which utilize neryl diphosphate or $(Z, Z)$-farnesyl diphosphate as substrates $[54,55]$, these TPS are members of the TPS-e subfamily and none of the VvTPS that we characterized belonged to this subfamily. In addition, a screen of the grapevine genome sequence did not reveal the presence of $Z$-isoprenyl diphosphate synthases (unpublished results, $M$.
Chavez, S. Aubourg, and J. Bohlmann), therefore, we did not include these alternative substrates when assaying for VvTPS activity. Products were analyzed by GCMS and the majority of VvTPS analyzed produced multiple products (Table 1 , Table 2 , Table 3 , and Table 4 ), which is a common feature of plant TPS [56,57]. Since many of the $V v T P S$ FLcDNAs arose from cloning efforts in all three $V$. vinifera varieties $\mathrm{PN}, \mathrm{CS}$, and $\mathrm{Gw}$, a number of $V v T P S$ were uncovered as cultivar-specific variants, each differing by only a few amino acids. To ensure that these were not unique genes capable of producing a distinct product profile, each variant was functionally 


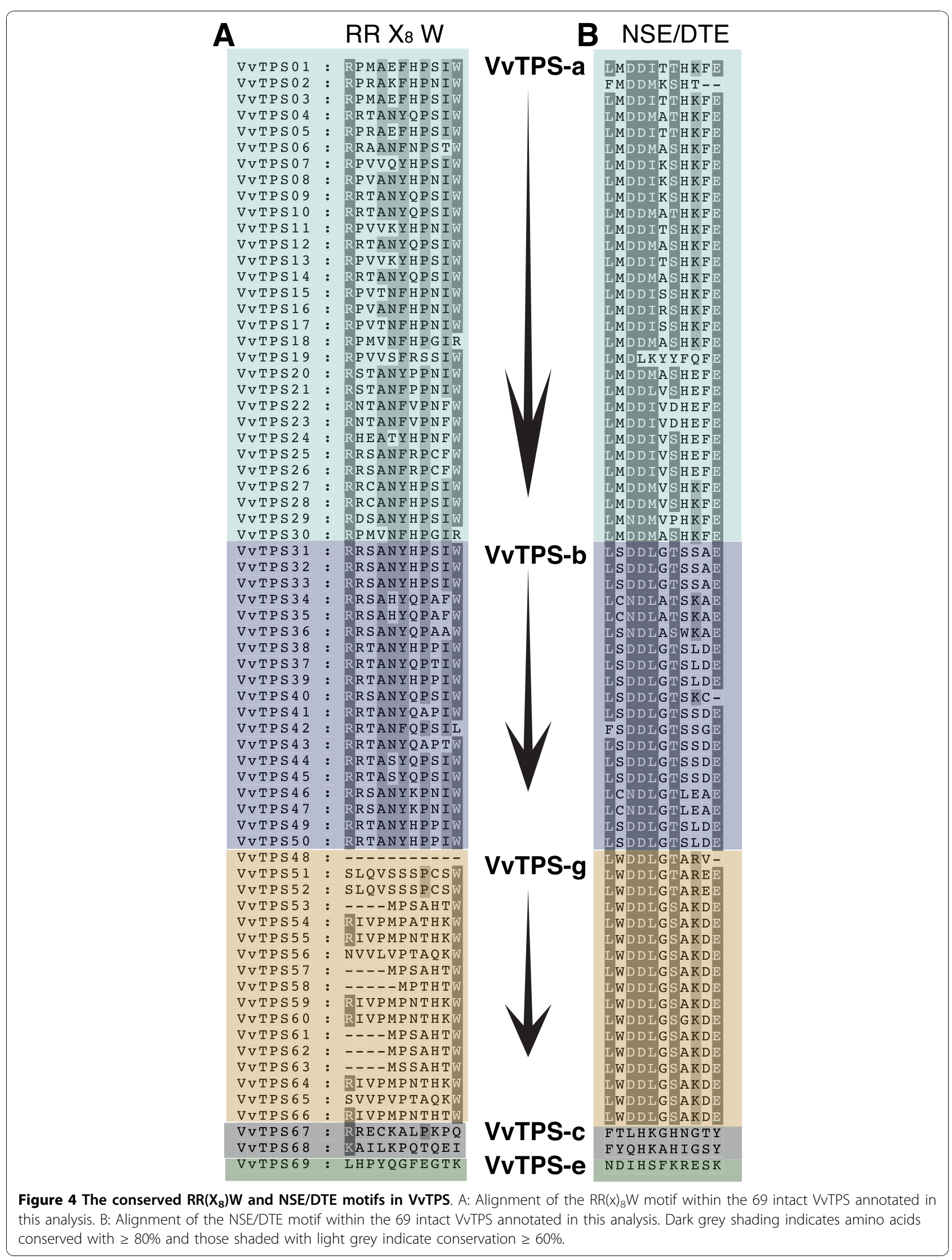


Table 1 Experimental Functional Annotation of VvTPS Genes of the VvTPS-a Subfamily

\begin{tabular}{|c|c|c|c|c|c|c|}
\hline $\begin{array}{c}\text { Functional Gene } \\
\text { ID }\end{array}$ & Function & Access. \# & FLcDNA ID & $\begin{array}{c}\text { Nearest VvTPS gene } \\
\text { model }\end{array}$ & $\begin{array}{r}\text { Representative } \\
\text { Products }\end{array}$ & $\%$ \\
\hline VvGwECar1 & \multirow[t]{5}{*}{ (E)- $\beta$-Caryophyllene Syn } & HM807373 & Gw38F6* & VVTPS01 & (E)-caryophyllene & 71 \\
\hline VvGwECar2 & & $\mathrm{HM} 807374$ & Gw53B1* & VVTPS27 & $\alpha$-humulene & 23 \\
\hline VvGwECar3 & & HM807375 & Gw12001M3* & VVTPSO2 & germacrene D & 6 \\
\hline VvPNECar1 & & $\mathrm{HM} 807402$ & CAN82172^ & VVTPSO2 & & \\
\hline VvPNECar2 & & HM807403 & CAO16256^ & VVTPS13 & & \\
\hline \multirow[t]{3}{*}{ VvGwGerA } & \multirow[t]{3}{*}{ Germacrene A Syn } & HQ326230 & Gw38F3* & VVTPS01 & germacrene $\mathrm{A}$ & 52 \\
\hline & & & & & $\alpha$-selinene & 24 \\
\hline & & & & & selin-11-en-4- $\alpha$-ol & 12 \\
\hline \multirow[t]{5}{*}{ VvGwaBer } & \multirow[t]{5}{*}{$(E)-\alpha$-Bergamotene Syn } & HM807376 & Gw56B1* & VVTPS10 & $(E)-\alpha$-bergamotene & 56 \\
\hline & & & & & Unknown & 17 \\
\hline & & & & & Nerolidol & 14 \\
\hline & & & & & (E)- $\beta$-farnesene & 8 \\
\hline & & & & & (Z)- $\alpha$-farnesene & 5 \\
\hline VvGwGerD & \multirow[t]{2}{*}{ Germacrene D Syn } & HM807377 & Gw64B1* & VVTPS07 & germacrene D & 94 \\
\hline VvPNGerD & & HM807378 & PN39M3* & VvTPS15 & germacrene B & 6 \\
\hline VvCSaFar & $(E, E)-\alpha$-Farnesene syn & HM807379 & $\mathrm{CS} 102 \mathrm{~B}^{*}$ & VVTPS20 & $(E, E)-\alpha$-farnesene & 100 \\
\hline \multirow[t]{2}{*}{ VvGwgCad } & \multirow[t]{2}{*}{$\gamma$-Cadinene Syn } & HM807380 & Gw330M5* & VVTPS08 & $\gamma$-cadinene & 83 \\
\hline & & & & & Unknown & 17 \\
\hline \multirow[t]{12}{*}{ VvPNbCur } & \multirow[t]{12}{*}{$\beta$-Curcumene syn } & HM807381 & PN62M1* & VvTPS30 & $\beta$-curcumene & 22 \\
\hline & & & & & (E)- $\gamma$-bisabolene & 18 \\
\hline & & & & & Iso-italicene & 16 \\
\hline & & & & & $(-)-\alpha$-bisabolol & 14 \\
\hline & & & & & B-bisabolene & 7 \\
\hline & & & & & epi- $\beta$-santalene & 7 \\
\hline & & & & & unknown & 5 \\
\hline & & & & & (E)- $\beta$-farnesene & 3 \\
\hline & & & & & $\gamma$-curcumene & 3 \\
\hline & & & & & unknown & 2 \\
\hline & & & & & (Z)- $\alpha$-bergomotene & 1 \\
\hline & & & & & unknown & 1 \\
\hline \multirow[t]{8}{*}{ VvPNSesq } & \multirow[t]{8}{*}{ Sesquithujene Syn } & HM807404 & CAO16252^ & VVTPS12 & (E)- $\alpha$-bergomotene & 1 \\
\hline & & & & & sesquithujene & 80 \\
\hline & & & & & $(E)$ - $\alpha$-bergamotene & 4 \\
\hline & & & & & sesquisabinene & 8 \\
\hline & & & & & $\beta$-bisabolene & 4 \\
\hline & & & & & $\gamma$-bisabolene & 2 \\
\hline & & & & & unknown pm 222 & 1.5 \\
\hline & & & & & $\beta$-bisabolol & 0.5 \\
\hline \multirow[t]{3}{*}{ VvPNaZin } & \multirow[t]{3}{*}{$\alpha$-Zingiberene syn } & HM807405 & CAO16257^ & VVTPS14 & $\alpha$-zingiberene & 79.5 \\
\hline & & & & & $\beta$-sesquiphellandrene & 17.5 \\
\hline & & & & & $\beta$-bisabolene & 3 \\
\hline \multirow[t]{7}{*}{ VvPNSelnt } & \multirow[t]{7}{*}{ Selina-411-diene/Interme deol syn } & HM807406 & CAO39293^ & VvTPS24 & selina-4,11-diene & 34 \\
\hline & & & & & intermedeol & 30 \\
\hline & & & & & 7-epi- $\alpha$-selinene & 15 \\
\hline & & & & & $\delta$-selinene & 14 \\
\hline & & & & & $\alpha$-guaiene & 3.5 \\
\hline & & & & & selina-511-diene & 2 \\
\hline & & & & & unknown pm 204 & 1 \\
\hline VvPNCUCad & Cubebol/ $\delta$-Cadinene syn & HM807407 & CAN76781^ & VvTPS26 & cubebol & 20.5 \\
\hline
\end{tabular}




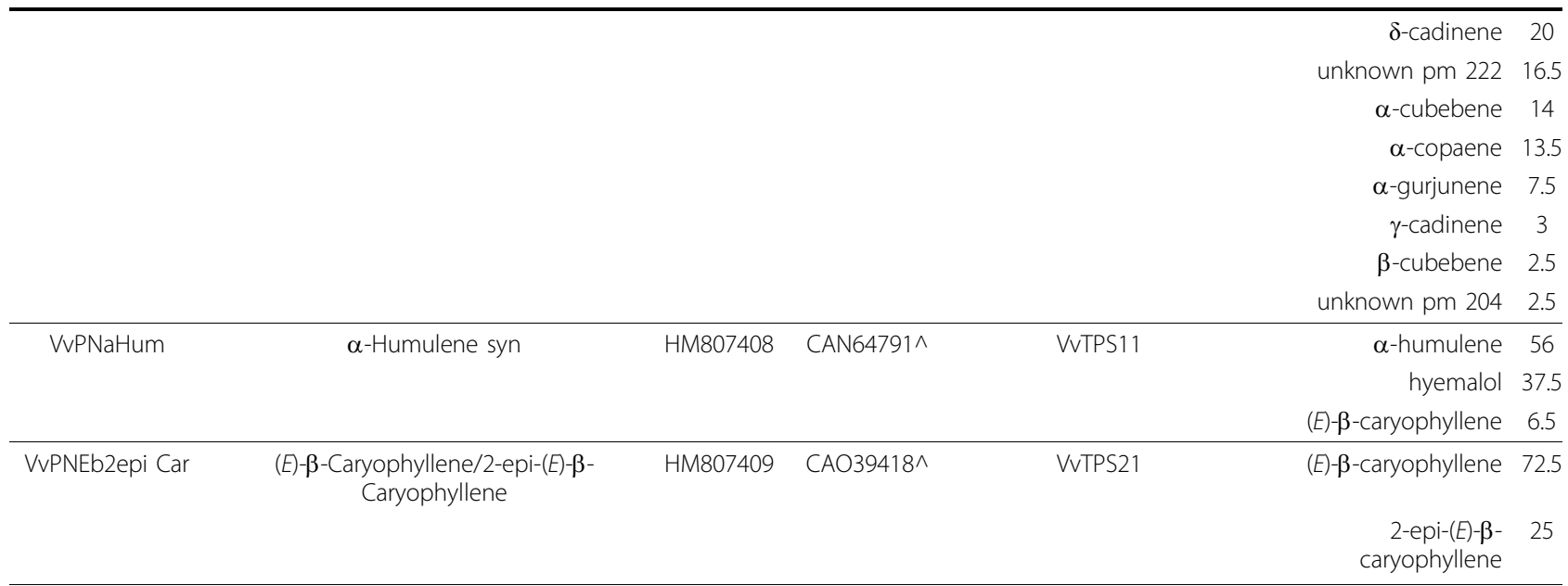

Terpenoids produced by individual VvTPS clones when incubated with FPP are listed. FLcDNA clones with redundant functions are listed as well. Clones marked with an * were characterized by in vitro assays with isolated recombinant VvTPS; clones marked with $\wedge$ were characterized in vivo in metabolically engineered $E$. coli. The tissue specific cDNA used to clone a particular gene is indicated in FLCDNA ID with either B (berry), F (flower), or M (mixed template consisting of stems, berries, flowers, and leaves) when appropriate. FLCDNA ID in bold indicates clone came from cDNA of methyl jasmonate treated tissue. Of the clones labelled as (E) $-\beta$-caryophyllene syn all produced an abundance of (E)- $\beta$-caryophyllene, with minor components of $\alpha$-humulene and germacrene $d$ except CAN82172 which did not produce germacrene D. Bolded VVTPS gene models indicate proof of transcript not previously known from the available ESTs.

characterized. However, only one representative cDNA clone will be described for its function following below, while the additional clones from the other cultivars are listed in Table 1, Table 2, Table 3, and Table 4.

A subset of $V v T P S$ FLcDNAs of the TPS- $a$ subfamily (Table 1 ) were chemically synthesized and characterized using an E. coli strain engineered to produce the FPP substrate from mevalonate. Based on previous work [58], an operon encoding the mevalonate lower pathway of Streptoccoccus pneumoniae was subcloned into a bacterial expression vector together with the Saccharomyces cerevisiae FPP synthase. VvTPS FLcDNAs were additionally expressed into this engineered strain and product formation was measured by GCMS in the culture extract as has been done for the characterization of other TPS and cytochrome P450 s [59].

\section{Nomenclature for functionally characterized VvTPS FLCDNAs}

We assigned gene identifiers that include references to both function and the cultivar (PN, CS, or Gw) from which the gene was isolated (see Functional Gene ID in Table 1, Table 2, Table 3, and Table 4). These functional gene identifiers will be used throughout the following sections to describe individual genes. Table 1, Table 2, Table 3, and Table 4 provide additional detailed information for each FLcDNA regarding clone ID, tissue origin (see table legend), product profiles with relative quantitative information, as well as identification of the closest annotated $V v T P S$ gene model reported in this paper. In some instances multiple cDNAs share the same functional gene identifier, but are represented as distinct genes because they occupy unique locations within the $V v T P S$ phylogeny. These functional gene IDs are designated with numbers in both the tables and within the phylogenetic trees.

\section{Functions of VvTPS FLCDNAs of the TPS-a Subfamily}

The majority of $V v T P S$ genes belong to the TPS-a subfamily for which we functionally characterized 13 unique FLcDNAs (Table 1). All of the VvTPS- $a$ members were characterized as sesquiterpene synthases, and all but one formed multiple products with FPP as substrate. In several cases, the product profiles included both terpenoid hydrocarbons and alcohols. As a group, the VvTPS of the TPS- $a$ subfamily produce a diverse array of sesquiterpene products.

All five individual VvGwECar and VvPNECar FLcDNA clones produced predominantly $(E)-\beta$-caryophyllene. Four of these clones also produced $\alpha$-humulene and a small amount of germacrene D, while one clone (CAN82172) produced only (E)- $\beta$-caryophyllene (94\%) and $\alpha$-humulene (6\%). The two VvPNECar enzymes characterized in metabolically engineered E. coli (clones CAO16256 and CAN82172) showed similar product profiles to VvGwECar clones characterized by in vitro enzyme assays. One of the VvPNECar enzyme (CAO16256) also produced a low amount $(<1 \%)$ of an unknown sesquiterpene alcohol in addition to $(E)$ - $\beta$-caryophyllene, $\alpha$-humulene and germacrene D. The TPS VvGwGerA (Gw38F3) produced primarily germacrene A (52\%) and $\alpha$-selinene (24\%) and a small amount of selin-11-en-4- $\alpha$-ol (12\%). The product profile of VvGwaBer (Gw56B1) consisted of $(E)$ - $\alpha$-bergamotene (56\%), zingiberenol (17\%) and nerolidol (14\%) as well as 
Table 2 Experimental Functional Annotation of VvTPS Genes of the VvTPS-b Subfamily

\begin{tabular}{|c|c|c|c|c|c|c|}
\hline $\begin{array}{l}\text { Functional Gene } \\
\text { ID }\end{array}$ & Function & Access. \# & FLcDNA ID & $\begin{array}{c}\text { Nearest VvTPS gene } \\
\text { model }\end{array}$ & $\begin{array}{r}\text { Representative } \\
\text { Products }\end{array}$ & $\%$ \\
\hline \multirow[t]{10}{*}{ VvGwaPhe } & (+)- $\alpha$-Phellandrene Syn & HM807382 & Gw74ME & VvTPS45 & (+)- $\alpha$-phellandrene & 40 \\
\hline & & & & & myrcene & 15 \\
\hline & & & & & terpinolene & 15 \\
\hline & & & & & $\alpha$-terpinene & 7 \\
\hline & & & & & $\gamma$-terpinene & 6 \\
\hline & & & & & (+)-limonene & 5 \\
\hline & & & & & $(+)-\alpha$-pinene & 3 \\
\hline & & & & & $(+)-\beta$-phellandrene & 3 \\
\hline & & & & & (+)- $\alpha$-terpineol & 3 \\
\hline & & & & & (E)- $\beta$-ocimene & 2 \\
\hline VvPNaPin1 & (+)- $\alpha$-Pinene Syn & HM807383 & PN20M1 & VvTPS44 & $(+)$ - $\alpha$-pinene & 47 \\
\hline \multirow[t]{10}{*}{ VvPNaPin2 } & & HM807384 & PN05S14 & VvTPS44 & (+)-limonene & 25 \\
\hline & & & & & (+)-camphene & 9 \\
\hline & & & & & myrcene & 6 \\
\hline & & & & & (+)- $\alpha$-terpineol & 5 \\
\hline & & & & & (+)-sabinene & 3 \\
\hline & & & & & (3S)-linalool & 2 \\
\hline & & & & & (+)- $\beta$-pinene & 1 \\
\hline & & & & & (+)- $\alpha$-phellandrene & 1 \\
\hline & & & & & (+)- $\alpha$-thujene & 1 \\
\hline & & & & & $\alpha$-terpinolene & 1 \\
\hline VvGwbOci & (E)- $\beta$-Ocimene syn & HM807385 & Gw22YB2 & VvTPS34 & $(E)-\beta$-ocimene & 98 \\
\hline VvCSbOci & & HM807386 & CS402F & VVTPS35 & $(Z)$ - $\beta$-ocimene & 2 \\
\hline \multirow[t]{4}{*}{ VvCSbOciM } & (E)- $\beta$-Ocimene/Myrcene syn & HM807387 & CS19M & VVTPS38 & (E)- $\beta$-ocimene & 53 \\
\hline & & & & & myrcene & 42 \\
\hline & & & & & $\beta$-pinene & 3 \\
\hline & & & & & limonene & 2 \\
\hline VvGwbOciF & $\begin{array}{c}(E)-\beta \text {-Ocimene } /(E E)-\alpha \text {-Farnesene } \\
\text { Syn }\end{array}$ & HM807388 & Gw46YB3 & VvTPS47 & (E)- $\beta$-ocimene & $100^{*}$ \\
\hline VvCSbOciF & & HM807389 & CS93F & VvTPS47 & $(E, E)-\alpha$-farnesene & $100^{* *}$ \\
\hline VvPNRLin & (3R)-Linalool syn & HM807390 & PNTPS09M1 & VvTPS31 & (3R)-linalool & 100 \\
\hline
\end{tabular}

Terpenoids produced by individual VvTPS clones when incubated with GPP are listed. Where noted are bifunctional TPS capable of producing products when incubated with GPP $\left(^{*}\right)$ or FPP $\left(^{* *}\right)$. The tissue specific CDNA used to clone a particular gene is indicated in FLCDNA ID with either B (berry), YB (young berry), $F$ (flower), S (stem) or M (mixed template consisting of stems, berries, flowers and leaves). FLcDNA ID in bold indicates clone came from cDNA of methyl jasmonate treated tissue. Clones with redundant functions are listed as well. Bolded VvTPS gene models indicate proof of transcript not previously known from the available ESTs.

two minor compounds. Germacrene D was the primary product of VvGwGerD (Gw64B1). VvCSAFar (CS102B7) was the only single-product member of the TPS- $a$ subfamily identified here, producing $100 \%(E, E)$ - $\alpha$-farnesene. Two products, $\gamma$-cadinene $(83 \%)$ and an unidentified sesquiterpene $(17 \%)$, were the only detected products of VvGwgCad (Gw330M5). VvPNbCur (PN62M1) produced $\beta$-curcumene (22\%) (E)- $\gamma$-bisabolene (18\%), iso-italicene) (16\%), (-)- $\alpha$-bisabolol (14\%), and at least 9 additional products. The VvPNSesq (CAO16252) generated a sesquiterpene olefin as major product that was not identified unambiguously by GCMS. The product was, therefore, produced in larger quantity, purified by preparative GC and identified by NMR spectroscopy as sesquithujene ((1 S,5S)-2-methyl-
5-((R)-6-methylhept-5-en-2-yl)bicyclo[3.1.0]hex-2-ene). Additional reaction products of this TPS included $\alpha$-bergamotene, sesquisabinene, $\beta$ - and $\gamma$-bisabolene, $\beta$-bisabolol and a trace amount of an unidentified sequiterpene alcohol. VvPNaZin (CAO16257) is a zingiberene synthase that also produced $\beta$-sesquiphellandrene and $\beta$-bisabolene. The two major products generated by VvPNSeInt (CAO39293) were found to be selina 4,11-diene and intermedeol. At least, five other sesquiterpenes including $\alpha$-guaiene, selina 5,11-diene, $\gamma$-selinene, and 7-epi- $\alpha$-selinene, were identified as reaction products. VvPNCuCAD (CAN76781) encodes a multi-product sesquiterpene synthase capable of producing cubebol, $\delta$-cadinene, $\alpha$-copaene, $\alpha$-cubebene and an unknown sesquiterpene alcohol as dominant reaction 
Table 3 Experimental Functional Annotation of VvTPS Genes of the VvTPS-g Subfamily

\begin{tabular}{|c|c|c|c|c|c|c|}
\hline $\begin{array}{l}\text { Functional Gene } \\
\text { ID }\end{array}$ & Function & Access. \# & FLcDNA ID & $\begin{array}{c}\text { Nearest VvTPS gene } \\
\text { model }\end{array}$ & $\begin{array}{r}\text { Representative } \\
\text { Products }\end{array}$ & $\%$ \\
\hline VvPNLinNer1 & (3S)- Linalool/(E)- Nerolidol syn & HM807391 & PN25M6 & VVTPS54 & (3S)-Linalool & $100^{*}$ \\
\hline VvPNLinNer2 & & HM807392 & PN55M1 & VVTPS56 & & \\
\hline VvCSLinNer & & HM807393 & CS2251F & VvTPS56 & (E)-Nerolidol & $100^{* *}$ \\
\hline VVPNLNGI1 & $\begin{array}{c}\text { Linalool/(E)- Nerolidol/(E,E)-Geranyl } \\
\text { linalool syn }\end{array}$ & HM807394 & PNTPS271M2 & VvTPS57 & (3S)-Linalool & $100^{*}$ \\
\hline VVPNLNGI2 & & HM807395 & PNTPS271M5 & VvTPS63 & (E)-Nerolidol & $100^{* *}$ \\
\hline VVPNLNGI3 & & HM807396 & PNTPS271M4 & VVTPS58 & $(E, E)$-Geranyl linalool & $100^{* * *}$ \\
\hline VVPNLNGI4 & & HM807397 & PN3M2 & VvTPS61 & & \\
\hline VvGwGer & Geraniol syn & HM807398 & Gw63YB3 & VvTPS52 & Geraniol & 100 \\
\hline VvCSGer & & HQ326231 & CS5M2 & VVTPS52 & & \\
\hline VvPNGer & & HM807399 & PN5L1 & VvTPS52 & & \\
\hline
\end{tabular}

Terpenoids produced by individual VvTPS clones when incubated with GPP $\left(^{*}\right)$ or FPP $(* *)$ are listed. Where noted are trifunctional TPS capable of producing products also with GGPP $\left(^{* *}\right)$. The tissue specific CDNA used to clone a particular gene is indicated in FLCDNA ID with either YB (young berry), $F$ (flower), $L$ (leaves) or M (mixed template consisting of stems, berries, flowers and leaves). FLCDNA ID in bold indicates clone came from cDNA of methyl jasmonate treated tissue. Clones with redundant functions are listed. Bolded VVTPS gene models indicate proof of transcript not previously known from the available ESTs.

products; additional minor products included $\alpha$-gurjunene, $\gamma$-cadinene, $\beta$-cubebene and an unknown sesquiterpene. The VvPNaHum (CAN64791) produced $\alpha$-humulene (56\%), (E)- $\beta$-caryophyllene (6.5\%) and a sesquiterpene alcohol (37.5\%) that we initially failed to identify by GCMS; the latter compound was then produced in milligram quantities, purified by liquid chromatography and identified by ${ }^{1} \mathrm{H}$ - and ${ }^{13} \mathrm{C}$-NMR spectroscopy as hyemalol (3,7,10,10-tetramethylcycloundeca-3,7-dien-1-ol) a humulane-type sesquiterpenoid recently discovered in Zanthoxylum hyemale [60]. VvPNEb/2epiCar (CAO39418), was identified as a third type of caryophyllene synthase, which in contrast to VvPNECar and VvGwECar also catalyzed the formation of 2-epi- $(E)-\beta$-caryophyllene as a substantial (25\%) product.

Collectively, these characterized VvTPS- $a$ enzymes produce some of the major sesquiterpenes identified from grapevine. Furthermore, the prevalence of VvTPS producing (E)- $\beta$-caryophyllene, $\alpha$-humulene and germacrene D may in part explain the reported prominence of these compounds in grapevine berries and vegetative tissues [12-15].

Functions of $V v T P S$ FLCDNAs of the TPS- $b$ subfamily We functionally characterized seven unique $V v T P S$ (nine different FLcDNA clones) from the TPS- $b$ subfamily
(Table 2). All of the characterized VvTPS genes of this group produce monoterpenes, and most are multi-product enzymes. The products of $\mathrm{VvGwaPhe}$ included (+)- $\alpha$-phellandrene (40\%), myrcene (15\%), terpinolene $(15 \%)$, and seven other minor products. VvPNaPIN produced (+)- $\alpha$-pinene (47\%), (+)-limonene (25\%), (+)-camphene $(9 \%)$, and eight other minor products. Five of the nine VvTPS of the TPS- $b$ subfamily (VvGwbOci, VvCSbOci, VvCSbOciM, VvGwbOciF, VvCSbOciF) produced $(E)-\beta$-ocimene as a major product with individual variations of additional products. VvGwbOci and VvCSbOci produced additional minor amounts of $(Z)-\beta$ ocimene; VvCSbOciM produced additional major amounts of myrcene (42\%) along with minor amounts of $\beta$-pinene and limonene; VvGwbOciF and VvCSbOciF also converted FPP into $(E, E)-\alpha$-farnesene. Lastly, VvPNRLin produced a single oxygenated product, $(3 R)$ linalool. Together the VvTPS- $b$ subfamily members account for many of the acyclic and cyclic monoterpene hydrocarbons and a few of the monoterpene alcohols found in Vitis vinifera.

\section{Functions of VvTPS FLCDNAs of the TPS-g subfamily}

The TPS-g subfamily is greatly expanded in $V$. vinifera (Figure 2, Addiitonal File 1). Functional characterization of ten different FLcDNA clones of this subfamily

Table 4 Experimental Functional Annotation of VvTPS Genes of the VvTPS-f Subfamily

\begin{tabular}{|c|c|c|c|c|c|c|}
\hline $\begin{array}{l}\text { Functional Gene } \\
\text { ID }\end{array}$ & Function & Access. \# & $\begin{array}{l}\text { FLCDNA } \\
\text { ID }\end{array}$ & $\begin{array}{l}\text { Nearest VvTPS gene } \\
\text { model }\end{array}$ & $\begin{array}{r}\text { Representative Product } \\
\text { Profile }\end{array}$ & $\%$ \\
\hline VvCSENerGl & $\begin{array}{c}\text { (E)-Nerolidol/(E,E)-Geranyl linalool } \\
\text { syn }\end{array}$ & HM807400 & CS34137F & NA & (E)-Nerolidol & $100^{*}$ \\
\hline VvPNENerGl & & HM807401 & PNTPS51F2 & NA & $(E, E)$-Geranyl linalool & $100^{* *}$ \\
\hline
\end{tabular}

Terpenoids produced by individual VvTPS clones when incubated with FPP $\left({ }^{*}\right)$ or GGPP $(* *)$ are listed. The tissue specific cDNA used to clone a particular gene is indicated in FLCDNA ID with $\mathrm{F}$ (flower). Clones with redundant functions are listed also. 
identified three unique gene functions (Table 3). All VvTPS of this group produce exclusively acyclic terpene alcohols, but the three types differ by their range of substrates. The first type of $V v T P S$ gene function within the TPS-g subfamily is represented by three genes, VvPNLinNer1, VvPNLinNer2, and VvCSLinNer. These enzymes accept two substrates, C10 GPP and C15 FPP, and produce (3S)-linalool and (E)-nerolidol, respectively (Table 3). The second group is represented by four VvPNLNGl enzymes which also accept the additional C20 substrate GGPP to produce $(E, E)$-geranyl linalool. The third unique function in this subfamily is represented by three genes, VvGwGer, VvCSGer and VvPNGer, which had activity only with GPP to produce geraniol. While seven of the VvTPS of the TPS- $g$ subfamily accept more than one substrate in vitro and contribute potentially to the formation of terpene alcohols of different chain lengths, it is not known whether these enzymes indeed encounter more than one type of substrate in vivo.

\section{Functions of $V v T P S$ FLCDNAs of the TPS-f subfamily}

Although the analysis of the 12 -fold genome sequence coverage did not identify any intact VvTPS genes of the TPS-f subfamily, a unique VvTPS function of the TPS- $f$ subfamily was characterized with the two FLcDNAs VvCSENerGl and VvPNENerGl (Table 4). These enzymes accepted either FPP or GGPP to produce $(E)$ nerolidol or $(E, E)$-geranyl linalool, respectively. Unlike the VvTPS of the TPS-g these enzymes had no activity with GPP. VvCSENerGl and VvPNENerGl are only $62 \%$ identical and $76 \%$ similar on an amino acid level.

\section{Phylogeny of functionally characterized VvTPS and VvTPS gene models}

The phylogenetic analyses presented here include $V$. vinifera TPS from the 12-fold sequence assembly of the nearly homozygous Pinot noir genotype [1] and the functionally characterized VvTPS described here. The analyses also included full-length TPS sequences that contained the known TPS motifs predicted from the genome assembly of the heterozygous Pinot noir genotype [36] for a more complete annotation of the $V v T P S$ family. In this way, we have integrated the predictions of $V v T P S$ gene models from the two grapevine genome sequences $[1,36]$ in a compatible fashion and we are proposing a unified $V v T P S$ classification and nomenclature.

Within the TPS-a subfamily of sesquiterpene synthases the functionally characterized VvTPS are close to most of the VVTPS predicted in the 12-fold genome sequence assembly (Figure 5). This topology suggests that the diversity of functions for grapevine sesquiterpene synthases is well represented with the functionally characterized VvTPS described in this work. Relative to TPS-a enzymes of other plant species, the VvTPS exhibit a large paralogous cluster with $V v T P S-a$ members more closely related to one another than they are to TPS from other species, regardless of function. Paralogous TPS gene clusters were found previously for other species examined in depth such as A. thaliana [16] and Norway spruce [56] and indicate post-speciation gene duplication events. The large number of VvTPS- $a$ suggests that this subfamily plays an important role in grapevine biology.

$V v T P S$ of the TPS- $b$ subfamily fall into two clades, $V \nu T P S-b$ clade I and $V \nu T P S-b$ clade II, bifurcated by representative TPS from other plants (Figure 6). The majority of the $V v T P S$ of clade I make cyclic products while those of clade II produce only acyclic terpenoids. It is possible that clade-specific conserved sequence features determine whether a TPS is able to produce cyclic or acyclic products [53]; thus, the two clades may represent an evolutionary pattern of sub-functionalization from cyclic-product TPS in clade I to those TPS producing acyclic products in clade II. In contrast to other TPS subfamilies, the VvTPS clades of the TPS- $b$ subfamily include members that have functional equivalents in distantly related species. For example, Lotus japonica (E)- $\beta$-ocimene synthase clusters closely with grapevine ocimene synthases. Malus $x$ domestica $(E, E)$ - $\alpha$-farnesene synthases also clusters closest to VvTPS of the same function. This pattern suggests that these functions arose prior to speciation events.

The TPS- $g$ subfamily of plant TPS was defined by previous work on TPS of floral scent biosynthesis in snapdragon (Anthirrrhinum majus) [37]. Phylogenetic analyses that include the large number of $V v T P S$ gene (Figure 1) conclusively resolved a bifurcation of the TPS- $b$ and TPS- $g$ subfamilies at a juncture that was previously ambiguous and had misclassified some TPS- $g$ genes as TPS- $b$ members. Specifically, the newly characterized grapevine geraniol synthase VvPNGer which matches gene model VvTPS52 (Figure 1) as well as the geraniol and linalool synthases from basil (Ocimum basilicum) (Figure 7), clustered closely with the TPS-g subfamily. The phylogenetic proximity between the basil and grapevine geraniol synthases indicates that these TPS functions already existed in a common ancestor. In contrast, the remaining VvTPS of the TPS-g subfamily, which are all linalool/nerolidol synthases, cluster closest to other VvTPS. As mentioned above, the entire predicted VvTPS- $g$ subfamily has a conserved NSF/DTE motif (Figure 4). This same motif is present in the cloned VVTPS cDNAs as well as other members of the TPS-g subfamily from different species. Prominent in this motif of the VvTPS-g members is a W in the second position; this residue may affect the magnesium binding 
and/or substrate orientation. Also noteworthy is the highly modified or absent $\mathrm{RRX}_{8} \mathrm{~W}$ motif from this group of TPS (Figure 4) and which may imply that these acyclic products are formed via the geranyl cation rather than the linalyl cation $[37,53]$.

The TPS- $e$ and TPS-c subfamilies in $V$. vinifera contain one and two members, respectively (Figure 8). Although these were not functionally characterized in this paper, they are almost certainly involved as diterpene synthases in ent-kaurene biosynthesis [61]. Surprisingly, the 12-fold sequence coverage of the grapevine genome did not reveal any members of the TPS-f subfamily; however, our FLcDNA cloning identified two members of this subfamily and both were characterized as nerolidol/geranyl linalool synthases (Figure 8). These are related to the Clarkia brewerii linalool synthases [62] and the recently characterized A. thaliana geranyl linalool synthase [20], each of which produces acyclic terpene alcohols as a functional signature of this subfamily.

\section{Conclusions}

The present study provides the first comprehensive annotation of the very large $V v T P S$ gene family with regard to chromosomal localization, enzyme functions, and phylogeny relative to the overall plant TPS gene family. The $V \nu T P S$ gene family is one of the largest gene families of specialized (i.e., secondary) metabolism in grapevine where TPS enzymes contribute to berry and wine flavour, floral scent and potentially a diversity of other biological functions such as defense and resistance. The emerging profile of the VvTPS family described here illustrates how this large gene family has expanded across the genome through gene duplication events and functional diversification. Notably, the large number of functionally diverse sesquiterpene synthases identified in our biochemical characterization of the $V v T P S-a$ genes suggests that these enzymes and their products may contribute substantially to grapevine biology and wine quality. The recent reports of sesquiterpenes in Shiraz grapes and wine $[10,11]$ or the identification of sesquiterpene volatiles in anthers and pollen of grapevine flowers [32] are early insights to the emerging roles for sesquiterpene metabolism in $V$. vinifera.

Phylogenetic analyses of the VvTPS show a result similar to many plant species studied thus far in that most of the VvTPS form clusters of paralogous genes within the plant TPS family. This finding indicates a dominant process of post-speciation gene duplications, although there are also examples of conserved TPS functions of a more ancient order. Furthermore, our analyses substantiate separation of the TPS- $b$ and the TPS- $g$ subfamilies. The separation based on sequence relatedness is matched by separation of gene functions, since all known members of the TPS- $g$ subfamily produce acyclic products.

Of the monoterpene synthases presented here, those that produce (3S)-linalool (VvTPS-g), geraniol (VvTPS$g$ ), and the previously identified $\alpha$-terpineol synthase $(V v T P S-b)$ will be of much interest to viticulturalists and wine makers as these are some of the most prevalent compounds responsible for the floral characteristics of aromatic varieties. Furthermore, compounds such as geraniol and linalool can be further modified in grape musts and wine to produce citronellol, rose oxide, and wine lactone $[63,64]$. Linalool and $\alpha$-terpineol have also been found to contribute to the character of nonaromatic red grapevine varieties [65]. It is conceivable that different viticultural regimes may modify the expression of these TPS in grape berries and can thereby impact the quality of the resultant wines.

While many of the terpenoid products of the VvTPS enzymes characterized here have been described in the viticulture and oenology literature $[8,66]$, still several have yet to be associated with traits in grapes or wine. Taken together, the present VvTPS genomic annotations and the VvTPS functional characterizations provide a reference framework for future studies, including transcript and protein expression profiling, as well as terpenoid molecular marker development through, for example association mapping.

\section{Methods}

\section{VVTPS gene discovery and manual annotation}

The predicted proteome of the 12-fold coverage grapevine genome sequence assembly (GenBank, NCBI project ID 18785; Genoscope website: http://www. genoscope.cns.fr/externe/GenomeBrowser/Vitis/) was screened with two HMM profiles of the PFAM motifs [45] PF01397 (N-terminal TPS domain) and PF03936 (TPS, metal binding domain). In addition, the 12-fold genome sequence assembly was screened (TBLASTN) with known TPS sequences from Swiss-Prot in order to be not dependent of the automatic annotation. The 152 loci exhibiting significant similarities with known TPS (all BLAST hits with an e-value lower than 1.e-4 were individually evaluated) were manually annotated to correct erroneous automatic annotation and to discriminate between complete, partial and pseudo-TPS. Genomic regions with similarities spanning on less than 50 amino acids with TPS have not been considered. The manual annotation is based on the results of the EuGène predictor-combiner software [67] that was specifically trained for Vitis vinifera, sequence alignments with previously characterized TPS proteins and related PFAM motifs, spliced alignments [68] of cognate EST and cDNA sequences and knowledge of TPS gene structure and 


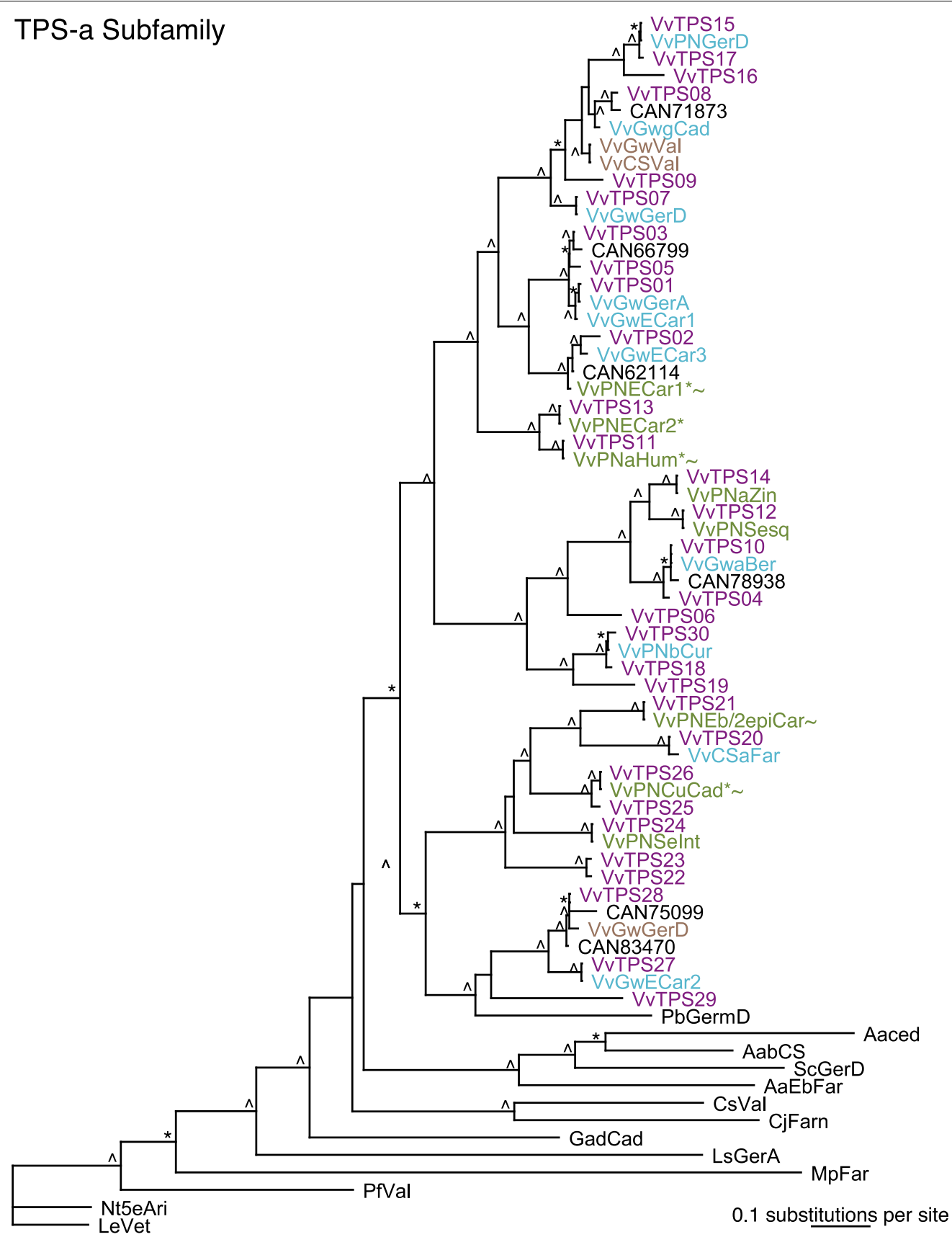

Figure 5 Phylogeny of the VvTPS-a subfamily. Maximum likelihood analysis of the $V$. vinifera TPS-a subfamily. Bootstrap values supported by $\geq 50 \%$ are designated ${ }^{*}$ and those with values $\geq 80 \%$ are indicated with $\wedge$. TPS characterized in this paper are in teal and include Vv(PN \& Gw) ECar\# = (E)-caryophyllene syn, VvPNGerA = germacrene A syn, VvGwaBer $=(E)$ - $\alpha$-bergamotene syn, Vv(PN \& Gw)GerD = germacrene D syn,

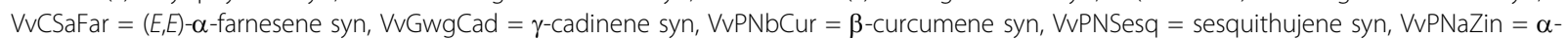
zingiberene syn, VvPNSelnt = Selina-4,11-diene/Intermedeol syn, VvPNCuCad $=$ cubebol/ $\delta$-cadinene syn, $V v P N a H u m=\alpha$-humulene syn, and VVPNEb2epiCar $=(E)-\beta$-caryophyllene/2 epi-(E)- $\beta$-caryophyllene syn. VVTPS predicted from the 12 -fold genome sequence assembly are in purple. Previously cloned VVTPS are in brown. TPS predicted by sequencing of the heterozygous Pinot noir are labeled with GenBank accession numbers (CAN...) or marked with $\sim$ if they were also cloned and characterized. Abbreviations are as follows: AabCS = Artemisia annua, $\beta$-caryophyllene syn (AAL79181), VvGwGerD = Vitis vinifera (-)-germacrene D syn (AAS66357), VvCsVal = V. vinifera (+)-valencene syn (ACO36239), Aaced = A. annua 8epi-cedrol syn (AAF80333), ScGerD = Solidago canadensis (-)-germacrene D syn (AAR31145), AaEbFar $=$ A. annua (E)- $\beta$-farnesene syn (AAX39387), CjFarn = Citrus junos (E)- $\beta$-farnesene syn (AAK54279), LsGerA = Lactuca sativa germacrene A syn (AAM1 1627), LeVet = Lycopersicon esculentum vetispiradiene syn (AAG09949), GadCad = Gossypium arboreum (+)- $\delta$-cadinene syn (O49853), PfVal = Perilla frutescens var. frutescens valencene syn (AAX16077), CsVal = C. sinensis valencene syn (AAQ04608), Nt5eAri = Nicotiana attenuata 5-epi-aristolochene syn $($ AAP05761), MpFar $=$ Mentha $x$ piperita (E)- $\beta$-farnesene syn (AAB95209). 


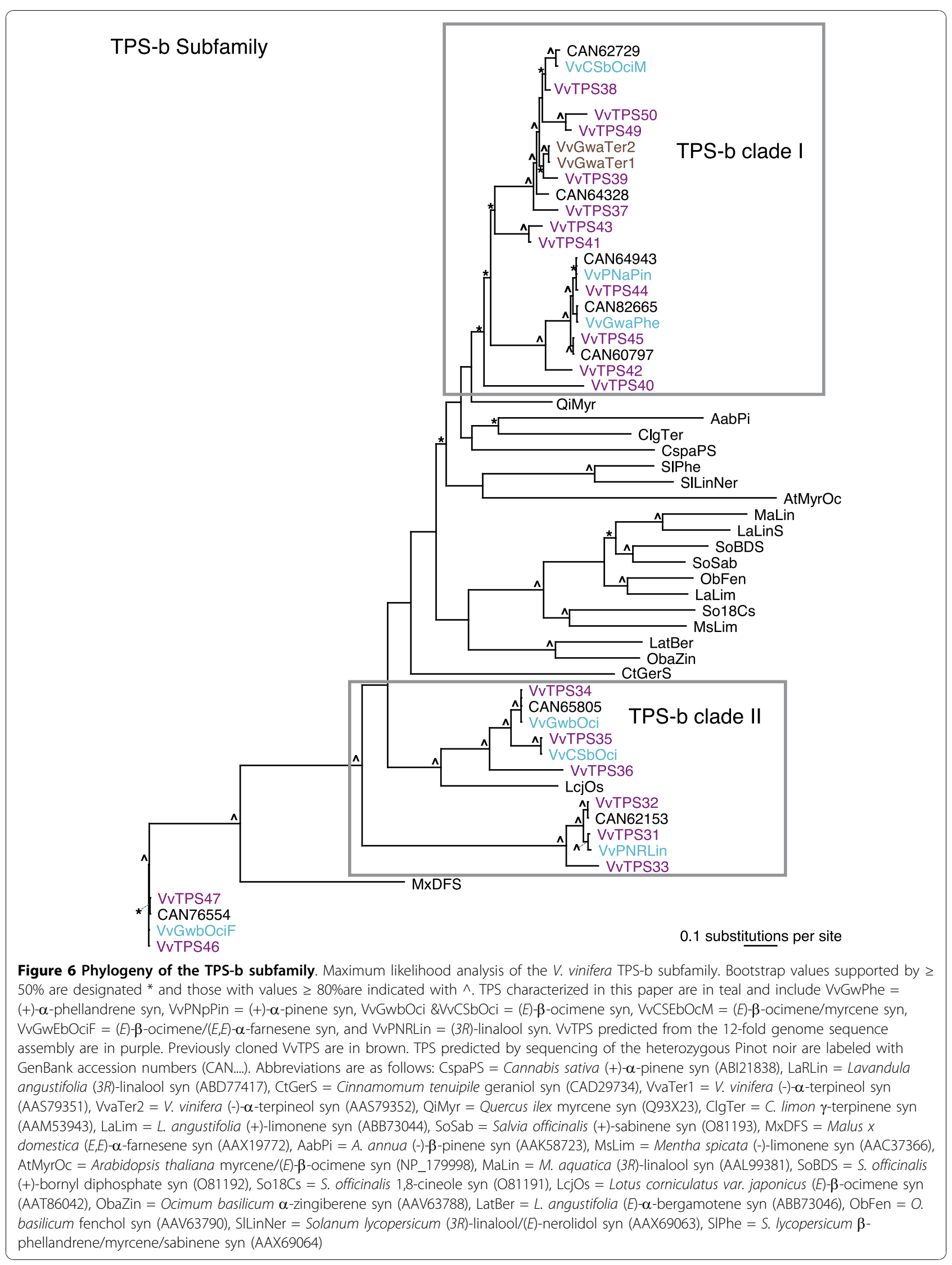




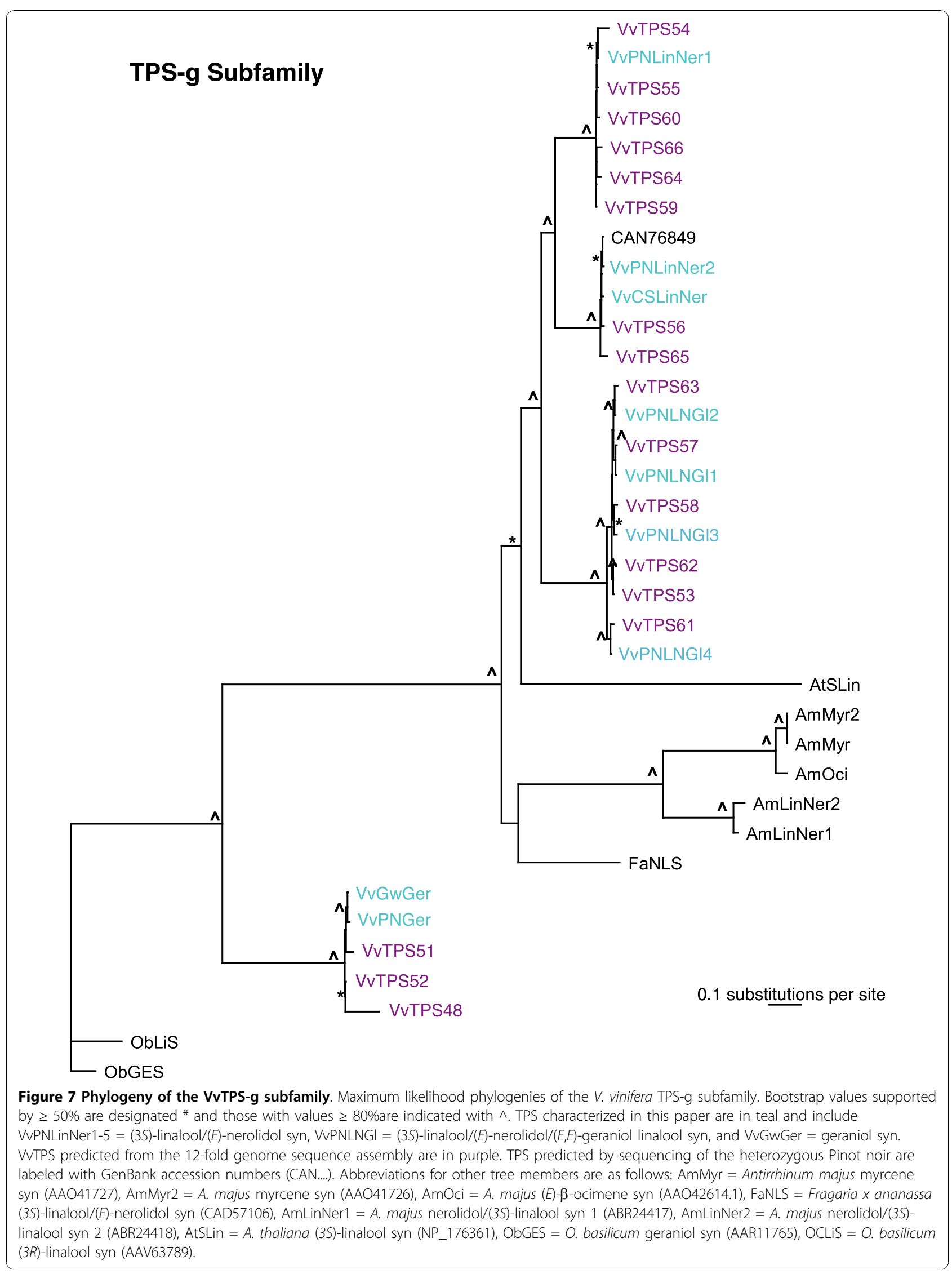




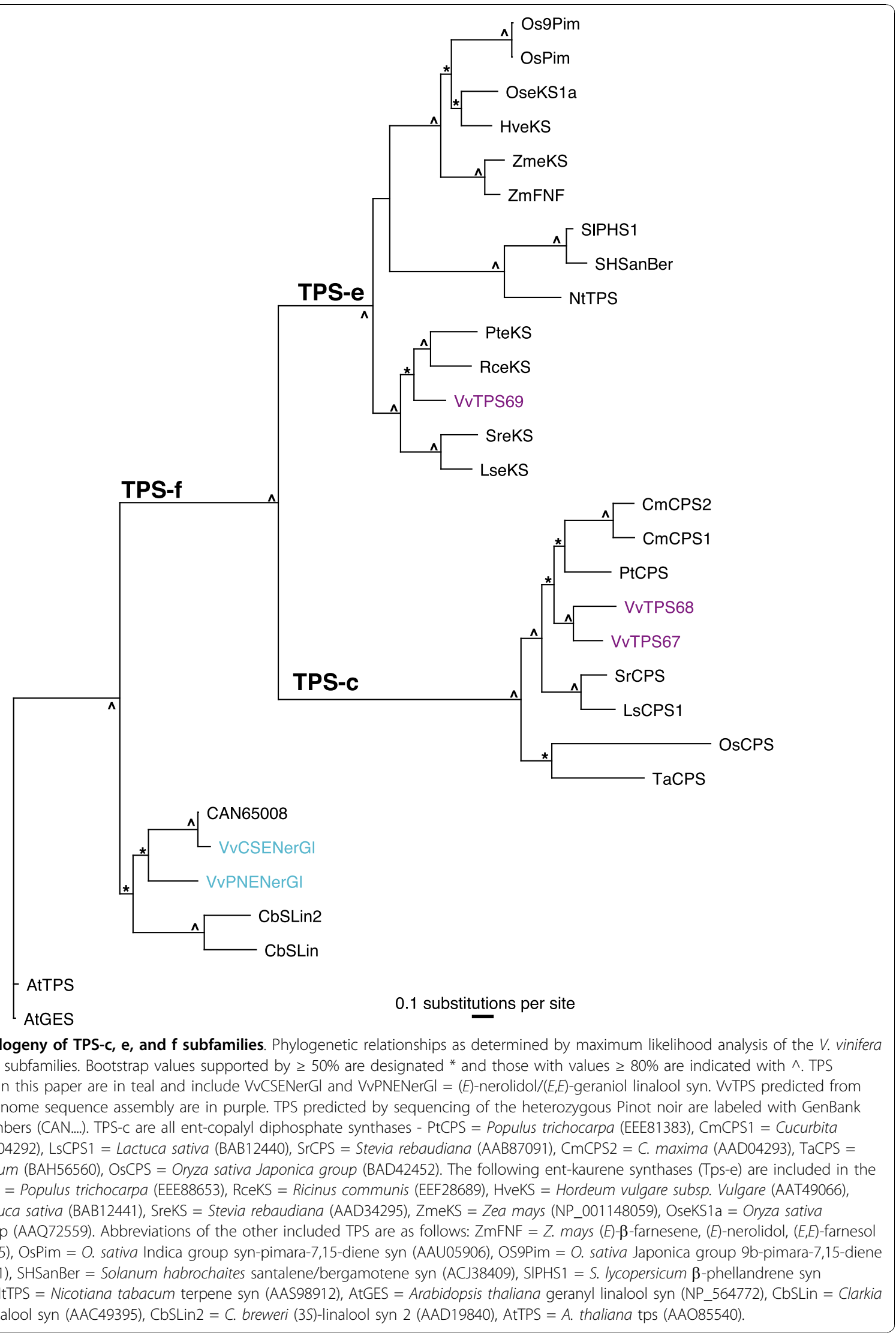


protein sequences. Data and other related information were imported and merged in the ARTEMIS tool [69] to evaluate each resource and produce the final annotation. The EuGène predictions, the manual structural annotation of the 152 loci and the corresponding sequences are available in the FLAGdb ${ }^{++}$database http://urgv.evry.inra.fr/FLAGdb[70]. Protein sequences deduced from the 69 full $V v T P S$ genes were analyzed with ChloroP for prediction of N-terminal plastidial targeting peptides [71]

\section{Phylogenetic Analyses}

Amino acid alignments were made using Dialign (dialign.gobics.de/anchor/submission.php) with a threshold value of 10. Manual adjustments such as aligning conserved motifs and manual trimming were performed using GeneDoc http://www.nrbsc.org/gfx/genedoc. For all analyses, sequence information upstream of the partially conserved $\mathrm{RR}(\mathrm{X})_{8} \mathrm{~W}$ motif was trimmed. Maximum likelihood analyses were completed using Phyml [72] available at http://www.atgc-montpellier.fr/phyml/. For each analysis, the LG amino acid substitution model and four substitution rate categories were used, the proportion of invariable sites and the gamma distribution parameter were estimated, and the branch lengths and tree topology were optimized from the data set. The estimated values for the proportion of invariable sites and the gamma shape parameter were then used when performing 100 bootstrap replicas. Phylogenetic trees were visualized using TreeView http://taxonomy.zoology.gla.ac.uk/rod/treeview.html.

\section{RNA isolation and VvTPS CDNA cloning}

RNA was isolated from Gewürztraminer, Pinot noir, and Cabernet Sauvignon grapevine shoot cuttings grown in the greenhouse as previously described [32]. RNA was isolated from stem (S), leaf (L), berry (B), root (R) and flower (F) tissues (see FLcDNA ID in Table 1, Table 2, Table 3, and Table 4) as detailed in Reid et al. [73]. To up-regulate expression of TPS genes, a subset of grapevine cuttings were treated with methyl jasmonate $(0.01 \%$ $\mathrm{v} / \mathrm{v}$ in water and $0.1 \%$ Tween) two days prior to RNA isolation. The Superscript Vilo cDNA synthesis kit (http://www.invitrogen.com was used according to the manufacturer's instructions. Primers for VvTPS cDNA cloning were designed based on TPS sequences obtained through iterative BLAST searches in NCBI GenBank using members of each of the TPS subfamilies. Additional information for the design of PCR primers came from the predicted $V v T P S$ gene models identified in the 12 -fold genome sequence assembly. To increase the likelihood of a successful PCR amplification of VvTPS cDNAs, cDNA templates from various tissues from the same cultivar were often combined. These clones are designated "M" for mixed template while those TPS cloned from individual tissues are labeled with the single letter abbreviations described above (Table 1, Table 2, Table 3, and Table 4). PCR reactions were done using touchdown PCR with proofreading polymerases, as per the product manufacturer's instructions. PCR products of the expected sizes were cloned into the pJet1.2 cloning vector http://www.fermentas.com and transformed into E. coli $\alpha$-select cells http://www.bioline.com. Plasmids containing a correctly sized insert were sequenced followed by insert amplification and ligation into the pET28b expression vector (Novagen, http://www.emdchemicals.com) using sticky end PCR [74]. When cloning difficulties were encountered, as was the case with several sequences, pASK-IBA3plus (IBA, http://www.ibago.com) vector was used [20].

\section{Expression of recombinant VvTPS proteins, in vitro enzyme assays and product identifications by GCMS}

For TPS protein expression, Cip41 Rare E. coli cells [75] containing recombinant $V v T P S$ plasmids were grown until $0.8 \mathrm{OD}$, induced with $0.5 \mathrm{mM}$ IPTG and then grown for an additional $16 \mathrm{~h}$ at $16{ }^{\circ} \mathrm{C}$. Recombinant VvTPS were partially purified using His SpinTrap columns (GE Biosciences, http://www.apbiotech.com). Protein expression was verified using silver stained SDSPAGE gels and western blot analysis using Murine antipolyHistidine Monoclonal antibody (1/4000 dilution, Sigma-Aldrich, http://www.sigmaaldrich.com) and 5-bromo-4-chloro-3-indolyl phosphate/nitro blue tetrazolium (CalBiochem, http://www.emdchemicals.com). For Strep-tag II clones, the pASK-IBA3plus vector combined with Cip41 Rare cells were used for expression and protein was isolated as per the manufacturer's instructions using a Strep-Tactin affinity purification column (IBA).

For functional enzyme characterization, approximately $100 \mu \mathrm{g}$ total protein of semi-purified recombinant VvTPS were added to a single vial assay in $50 \mu \mathrm{L}$ total volume as described $[32,75,76]$. Each recombinant VvTPS was incubated with GPP $(109 \mu \mathrm{M}),(E, E)$-FPP $(92 \mu \mathrm{M})$ or $(E, E, E)$-GGPP $(20 \mu \mathrm{M})$ for $2 \mathrm{~h}$ at $30{ }^{\circ} \mathrm{C}$. Buffers used for sesquiterpene and diterpene synthase assays contained $50 \mathrm{mM}$ HEPES $\mathrm{pH} 7.0,10 \mathrm{mM} \mathrm{MgCl}_{2}$, $20 \mu \mathrm{M} \mathrm{MnCl}_{2}, 10 \%$ glycerol (v/v), and $1 \mathrm{mM}$ DTT. For monoterpene synthase assays, the buffer consisted of 50 $\mathrm{mM}$ HEPES $\mathrm{pH}$ 7.0, $10 \mathrm{mM} \mathrm{MgCl}, 20 \mu \mathrm{M} \mathrm{MnCl}_{2} 100$ $\mathrm{mM} \mathrm{KCl}, 10 \%$ glycerol (v/v), and $1 \mathrm{mM} \mathrm{DTT}$.

Gas chromatography coupled with mass spectrometry (GCMS) analysis was employed to determine the product profiles of each TPS as previously described $[32,56]$. Columns used to separate product mixtures included HP-5MS (Agilent), DB-Wax (Agilent), SolGelWax (SGE), and Cyclodex-B (Aglient) for chiral analyses. For sesquiterpene analysis, a cool-on column inlet 
(starting temperature of $35{ }^{\circ} \mathrm{C}$ and track oven program after injection) was used to prevent thermo-rearrangements of terpenes in the injector. Identities of individual terpenes were made using a combination of authentic standards and/or retention indices along with MS library matches (including WileyNist 2005, [77], and/or MassFinder4 [massfinder.com/wiki/MassFinder_4]).

\section{In vivo enzyme assays using metabolically engineered \\ E. coli}

A subset of $V v T P S$ encoding sesquiterpene synthases were codon-optimized for expression in E. coli, using gene synthesis by DNA2.0 https://www.dna20.com/ and subcloned into the pET-3a or pET-Duet1 expression plasmids (Novagen, http://www.emdchemicals.com). Enzymatic activity was assessed in E. coli cells coexpressing the TPS together with the enzymes of a fivestep biosynthetic pathway converting mevalonic acid to FPP. The FPP synthase gene was amplified from S. cerevisiae genomic DNA and ligated into the first multiple cloning site (MCS) of the pACYCDuet-1 expression plasmid (Novagen, http://www.emdchemicals.com) providing the plasmid FPPs-pACYCDuet. An operon encoding the genes for a mevalonate kinase (MvaK1), a phosphomevalonate kinase (MvaK2), a mevalonate diphosphate decarboxylase (MvaD) and an isopentenyl diphospahte isomerase (idi) was amplified from genomic DNA of Streptococcus pneumoniae (ATCC BAA-334) and ligated into the second MCS of the FPPs-pACYCDuet plasmid providing the plasmid pACYCDuet-4506. BL21 Star ${ }^{\mathrm{m}}(\mathrm{DE} 3)$ E. coli cells http://www.invitrogen.com were co-transformed with the plasmids, pACYCDuet4506 and either of the pET series plasmids harboring candidate VvTPS coding sequences. Single colonies were used to inoculate $5 \mathrm{~mL}$ of LB medium supplemented with carbenicillin $(50 \mathrm{mg} / \mathrm{mL})$ and chloramphenicol $(34$ $\mathrm{mg} / \mathrm{mL}$ ). Cultures were incubated overnight at $37^{\circ} \mathrm{C}$. The next day $250 \mathrm{~mL}$ to $1 \mathrm{~L}$ of Terrific Broth medium supplemented with the appropriate antibiotics were inoculated with $1 / 100$ volume of the overnight culture. After $6 \mathrm{~h}$ incubation at $37^{\circ} \mathrm{C}$, cultures were cooled down to $28^{\circ} \mathrm{C}$ and then $1 \mathrm{mM}$ IPTG, $2 \mathrm{mg} / \mathrm{mL}$ mevalonate prepared by dissolving mevalonolactone http://www.sigmaaldrich.com in $0.5 \mathrm{~N} \mathrm{NaOH}$ at a concentration of $1 \mathrm{~g} /$ $\mathrm{mL}$ and incubating the solution for $30 \mathrm{~min}$ at $37^{\circ} \mathrm{C}$ ) and 0.1 volume of decane were added to the cultures. After $48 \mathrm{~h}$ incubation, the decane fraction was directly analysed by GCMS on a Hewlett Packard 6890 series GC system equipped with a DB1 column $30 \mathrm{~m} \times 0.25 \mathrm{~mm} \times$ $0.25 \mathrm{~mm}$ film thickness http://www.agilent.com and coupled with a 5975 series mass spectrometer. The carrier gas was helium at a constant flow of $1 \mathrm{ml} \cdot \mathrm{min}^{-1}$. Injection was in splitless mode with the injector temperature set at $120^{\circ} \mathrm{C}$ and the oven temperature was programmed from $60^{\circ} \mathrm{C}$ to $265^{\circ} \mathrm{C}$ at $5^{\circ} \mathrm{C} \cdot \mathrm{min}^{-1}$. Identification of VvTPS products was based on retention time index, mass spectra of authentic standards, and on published [78] or Firmenich MS database. Co-injections were also used for some of the compounds (caryophyllene, humulene, cubebol, cubebene, intermedeol). For compounds that could not be identified by GCMS, the products were purified and their structures determined by NMR spectroscopy. Sesquithujene was isolated using manual, preparative-GC. The crude sample (bi-phasic bacteria culture) was first distilled using a Fisher column to remove the decane (temperature: $95{ }^{\circ} \mathrm{C}$; pressure: 25 mbar). The compounds were then separated using a GC equipped with a.1.83 $\mathrm{m} \times 2.1 \mathrm{~mm}$ i.d., $10 \% \mathrm{OV}-1$ packed column at a flow rate of $10 \mathrm{~mL} / \mathrm{min}$. The oven temperature was programmed from $160{ }^{\circ} \mathrm{C}$ (held 10 minutes) to $230{ }^{\circ} \mathrm{C}$ at $10{ }^{\circ} \mathrm{C} / \mathrm{min}$. Helium was used as the carrier gas. Hyemalol was purified by silica gel flash column chromatography (Silicagel $60,12 * 150 \mathrm{~mm}, 40$ $63 \mu \mathrm{M}$, Merck) using a 98:2 mixture of toluene and diethyl ether as solvent system. NMR data were acquired at $298 \mathrm{~K}$ using a Bruker Avance $500 \mathrm{MHz}$ spectrometer. The structure was established by $1 \mathrm{D}^{1} \mathrm{H}-$ and ${ }^{13} \mathrm{C}$ - NMR, as well as $2 \mathrm{D}$ HSQC, COSY and HMBC experiments.

\section{Additional material}

Additional file 1: The Excel file contains all the information relative to the 152 TPS loci detected and curated in the 12-fold PN40024 grapevine genome. The content of each column is: - Name: VVTPS nomenclature for the 69 complete terpene synthases. - Gene ID (12x): The official ID of the gene automatically annotated by IGGP (International Grape Genome Program) and used by GenBank/EMBL. The genes called 'newX' correspond to TPS loci completely missed by the automatic annotation pipeline. The curated gene structures and sequences are available in the FLAGdb ${ }^{++}$database http://urgv.evry.inra.fr/ FLAGdb. - merged ID: If the re-annotated TPS genes fit or overlap with several IGGP consecutive genes (erroneous splitting of the automatic annotation), their IDs are mentioned here. - Prot size: The size (in amino acids) of the re-annotated TPS proteins. For not complete or coherent CDS (partial or pseudo-TPS), the size fits with the longest rebuilt protein sequence (in italic). - Chr: The chromosome number. '10R' means that the gene is on the chromosome 10 but on a not mapped scaffold. ' $R$ ' means that the gene is inside an unmapped scaffold. - Exons: Number of annotated exons in the CDS (after curation). - Subfamily: Classification of TPS (TPS-a to TPS-g) according to the phylogeny and functional studies. The table is colored according to this column. - DDxxD: 'yes' means that the exact motif is present at the expected position (end of the exon 4). '?' means that the corresponding part of the gene is absent (partial gene or pseudogene). - RRx(8)W: 'yes' means that the exact motif is present at the expected position (end of the exon 1). '?' means that the corresponding part of the gene is absent (partial gene or pseudogene). NSE/DTE: sequence of the NSE/DTE motif present in the C-terminal region of the proteins from TPS-a, $-b$ and $-g$ subfamilies. - Start: first position of the curated CDS in the 12-fold pseudo-chromosomes. - Stop: last position of the curated CDS in the 12-fold pseudo-chromosomes. Strand: ' $m$ ' means minus strand and ' $p$ ' means plus strand relatively to the pseudo-chromosomes. - Manual re-annotation result: information about the evaluation and curation process. Protein IDs are listed for the VVTPS genes where automatic annotation predicted a correct structure. Type: 'full' means that the TPS gene (CDS) is complete, without sequence 
problem. 'full ?' means that CDS is complete excepted one punctual sequence problem. A sequencing error is therefore possible and the gene could be functional. 'partial' means that the gene is disrupted by an un-sequenced region (gap of $\mathrm{N}$ ) and additional sequencing is necessary to have a full CDS. 'pseudo' means that the gene structure is disturbed by stop(s) in frame, frameshift(s) and/or deletion(s). As it is, the gene cannot be functional and is qualified as pseudogene. - EST: The number of available cognate transcript sequences. $(+)$ means that the CDS is fully covered by the EST contig. - Note: Additional information about the partial genes and pseudogenes (nature of the problem, gap positions....). - Cluster: TPS with the same letter are organized in tandem in the same physical cluster. - Subcell. loc.: The result of the ChloroP prediction tool. A score greater than 0.5 means that the TPS protein is probably targeted to the plastids. ' $x$ ' means that the prediction has not been done because the N-terminal region of the protein is lacking. - Best hit in SwissProt: Biochemical function of the first hit obtained in the SwissProt database with BLASTP.

\section{Abbreviations}

VVTPS: Vitis vinifera terpene synthase; AtTPS: Arabidopsis thaliana terpene synthase; FLCDNA: full length CDNA; PN: Pinot noir; CS: Cabernet Sauvignon; Gw: Gewürztraminer; FPP: farnesyl diphosphate; GPP: geranyl diphosphate; GGPP: geranylgeranyl diphosphate.

\section{Acknowledgements}

We are grateful to Eric J. Abbott for bioinformatics and technical work on the cloning of TPS. We acknowledge Vincor International for allowing us to collect grape shoot material from their vineyards in Okanagan Falls, BC, and Osoyoos, BC. DMM was supported by a postdoctoral fellowship from the Natural Sciences and Engineering Research Council of Canada (NSERC). Salary support for JB was provided, in part, by the UBC Distinguished University Scholar program. Funding for this project was provided by the Natural Sciences and Engineering Research Council of Canada (to JB), Genome British Columbia, and Genome Canada (to JB and STL). Fabienne Deguerry, Laurence Pastore and Eggen Xian-Wen Gan (Firmenich SA) are thanked for excellent technical assistance.

\section{Author details}

'Michael Smith Laboratories, University of British Columbia, 2185 East Mall, Vancouver, B.C, V6T 1Z4, Canada. ${ }^{2}$ Wine Research Centre, University of British Columbia, 2205 East Mall, Vancouver, B.C., V6T 1Z4, Canada. ${ }^{3}$ Unité de Recherche en Génomique Végétale (URGV) UMR INRA 1165 - Université d'Evry Val d'Essonne - ERL CNRS 8196, 2 Rue Gaston Crémieux, 91057 Evry Cedex, France. ${ }^{4}$ Firmenich SA, Corporate R\&D Division, Geneva, CH-1211, Switzerland.

\section{Authors' contributions}

DMM, OT, MBS, LD, and SA, performed experiments and analyzed data. $D M M, J B, L D, M S$ and SA conceived of the study, interpreted results and wrote the paper. OT, LD, MS and STL reviewed the paper prior to submission and provided valuable comments on the interpretation and presentation of results. JB and STL secured funding. All authors read and approved the final manuscript.

\section{Received: 3 August 2010 Accepted: 21 October 2010}

Published: 21 October 2010

\section{References}

1. Jaillon O, Aury JM, Noel B, Policriti A, Clepet C, Casagrande A, Choisne N, Aubourg S, Vitulo N, Jubin C, Vezzi A, Legeai F, Hugueney P, Dasilva C, Horner D, Mica E, Jublot D, Poulain J, Bruyere C, Billault A, Segurens B, Gouyvenoux M, Ugarte E, Cattonaro F, Anthouard V, Vico V, Del Fabbro C, Alaux M, Di Gaspero G, Dumas V, Felice N, Paillard S, Juman I, Moroldo M, Scalabrin S, Canaguier A, Le Clainche I, Malacrida G, Durand E, Pesole G, Laucou V, Chatelet P, Merdinoglu D, Delledonne M, Pezzotti M, Lecharny A, Scarpelli C, Artiguenave F, Pe ME, Valle G, Morgante M, Caboche M, AdamBlondon AF, Weissenbach J, Quetier F, Wincker P: The grapevine genome sequence suggests ancestral hexaploidization in major angiosperm phyla. Nature 2007, 449:463-467.

2. Bohlmann J, Keeling Cl: Terpenoid biomaterials. Plant J 2008, 54:656-669

3. Dudareva N, Pichersky E: Floral Scent Metabolic Pathways: Their Regulation and Evolution. In Biology of Floral Scent. Edited by: Dudareva N, Pichersky E. Boca Raton: CRC Press; 2006:55-78.

4. Schwab W, Davidovich-Rikanati R, Lewinsohn E: Biosynthesis of plantderived flavor compounds. Plant J 2008, 54:712-732.

5. Christianson DW: Unearthing the roots of the terpenome. Curr Opin Chem Biol 2008, 12:141-150.

6. O'Maille PE, Malone A, Dellas N, Andes Hess BJ, Smentek L, Sheehan I, Greenhagen BT, Chappell J, Manning G, Noel JP: Quantitative exploration of the catalytic landscape separating divergent plant sesquiterpene synthases. Nat Chem Biol 2008, 4:617-623.

7. Lund ST, Bohlmann J: The molecular basis for wine grape quality - a volatile subject. Science 2006, 311:804-805.

8. Swiegers JH, Bartowsky EJ, Henschke PA, Pretorius IS: Yeast and bacterial modulation of wine aroma and flavour. Aust I Grape Wine Res 2005, 11:139-173.

9. Rapp A, Mandery H: Wine aroma. Experientia 1986, 42:873-884.

10. Parker M, Pollnitz AP, Cozzolino D, Francis IL, Herderich MJ: Identification and quantification of a marker compound for 'pepper' aroma and flavor in shiraz grape berries by combination of chemometrics and gas chromatography-mass spectrometry. J Agric Food Chem 2007, 55:5948-5955.

11. Siebert TE, Wood C, Elsey GM, Pollnitz AP: Determination of rotundone, the pepper aroma impact compound, in grapes and wine. J Agric Food Chem 2008, 56:3745-3748.

12. Kalua CM, Boss PK: Evolution of volatile compounds during the development of Cabernet Sauvignon grapes (Vitis vinifera L.). J Agric Food Chem 2009.

13. Tasin M, Anfora G, loriatti C, Carlin S, De Cristofaro A, Schmidt S, Bengtsson M, Versini G, Witzgall P: Antennal and behavioral responses of grapevine moth Lobesia botrana females to volatiles from grapevine. J Chem Ecol 2005, 31:77-87.

14. Loughrin JH, Potter DA, Hamilton-Kemp TR, Byers ME: Diurnal emission of volatile compounds by Japanese beetle-damaged grape leaves. Phytochemistry 1997, 45:919-923.

15. Hampel D, Mosandl A, Wüst M: Induction of de novo volatile terpene biosynthesis via cytosolic and plastidial pathways by methyl jasmonate in foliage of Vitis vinifera L. J Agric Food Chem 2005, 53:2652.

16. Aubourg S, Lecharny A, Bohlmann J: Genomic analysis of the terpenoid synthase (AtTPS) gene family of Arabidopsis thaliana. Mol Genet Genomics 2002, 267:730-745.

17. Bohlmann J, Martin D, Oldham NJ, Gershenzon J: Terpenoid secondary metabolism in Arabidopsis thaliana: CDNA cloning, characterization, and functional expression of a myrcene/(E)-beta-ocimene synthase. Arch Biochem Biophys 2000, 375:261-269.

18. Chen F, Ro DK, Petri J, Gershenzon J, Bohlmann J, Pichersky E, Tholl D: Characterization of a root-specific Arabidopsis terpene synthase responsible for the formation of the volatile monoterpene 1,8-cineole. Plant Physiol 2004, 135:1956-1966.

19. Chen F, Tholl D, D'Auria JC, Farooq A, Pichersky E, Gershenzon J: Biosynthesis and emission of terpenoid volatiles from Arabidopsis flowers. Plant Cell 2003, 15:481-494.

20. Herde M, Gartner K, Kollner TG, Fode B, Boland W, Gershenzon J, Gatz C, Tholl D: Identification and regulation of TPS04/GES, an Arabidopsis geranyllinalool synthase catalyzing the first step in the formation of the insect-induced volatile C16-homoterpene TMTT. Plant Cell 2008, 20:1152-1168.

21. Harris $\sqcup$, Saparno A, Johnston A, Prisic S, Xu M, Allard S, Kathiresan A, Ouellet T, Peters RJ: The maize An2 gene is induced by Fusarium attack and encodes an ent-copalyl diphosphate synthase. Plant Mol Biol 2005, 59:881-894.

22. Morrone $D$, Jin $Y, X u$ M, Choi SY, Coates RM, Peters RJ: An unexpected diterpene cyclase from rice: functional identification of a stemodene synthase. Arch Biochem Biophys 2006, 448:133-140.

23. Prisic $S, X u M$, Wilderman PR, Peters RJ: Rice contains two disparate entcopalyl diphosphate synthases with distinct metabolic functions. Plant Physiol 2004, 136:4228-4236. 
24. Wilderman PR, Xu M, Jin Y, Coates RM, Peters RJ: Identification of synpimara-7,15-diene synthase reveals functional clustering of terpene synthases involved in rice phytoalexin/allelochemical biosynthesis. Plant Physiol 2004, 135:2098-2105.

25. Xu M, Hillwig ML, Prisic S, Coates RM, Peters RJ: Functional identification of rice syn-copalyl diphosphate synthase and its role in initiating biosynthesis of diterpenoid phytoalexin/allelopathic natural products. Plant J 2004, 39:309-318.

26. Xu M, Wilderman PR, Morrone $D, X u J$, Roy A, Margis-Pinheiro M, Upadhyaya NM, Coates RM, Peters RJ: Functional characterization of the rice kaurene synthase-like gene family. Phytochemistry 2007, 68:312-326.

27. Tuskan GA, Difazio S, Jansson S, Bohlmann J, Grigoriev I, Hellsten U, Putnam N, Ralph S, Rombauts S, Salamov A, Schein J, Sterck L, Aerts A, Bhalerao RR, Bhalerao RP, Blaudez D, Boerjan W, Brun A, Brunner A, Busov V, Campbell M, Carlson J, Chalot M, Chapman J, Chen GL, Cooper D, Coutinho PM, Couturier J, Covert S, Cronk Q, Cunningham R, Davis J, Degroeve S, Dejardin A, Depamphilis C, Detter J, Dirks B, Dubchak I, Duplessis S, Ehlting J, Ellis B, Gendler K, Goodstein D, Gribskov M, Grimwood J, Groover A, Gunter L, Hamberger B, Heinze B, Helariutta Y, Henrissat B, Holligan D, Holt R, Huang W, Islam-Faridi N, Jones S, JonesRhoades M, Jorgensen R, Joshi C, Kangasjarvi J, Karlsson J, Kelleher C, Kirkpatrick R, Kirst M, Kohler A, Kalluri U, Larimer F, Leebens-Mack J, Leple JC, Locascio P, Lou Y, Lucas S, Martin F, Montanini B, Napoli C, Nelson DR, Nelson C, Nieminen K, Nilsson O, Pereda V, Peter G, Philippe R, Pilate G, Poliakov A, Razumovskaya J, Richardson P, Rinaldi C, Ritland K, Rouze P, Ryaboy D, Schmutz J, Schrader J, Segerman B, Shin H, Siddiqui A, Sterky F, Terry A, Tsai CJ, Uberbacher E, Unneberg P, Vahala J, Wall K, Wessler S, Yang G, Yin T, Douglas C, Marra M, Sandberg G, Van de Peer Y, Rokhsar D: The genome of black cottonwood, Populus trichocarpa (Torr. \& Gray). Science 2006, 313:1596-1604

28. Arimura G, Huber DP, Bohlmann J: Forest tent caterpillars (Malacosoma disstria) induce local and systemic diurnal emissions of terpenoid volatiles in hybrid poplar (Populus trichocarpa x deltoides). Plant J 2004, 37:603-616.

29. Miller B, Oschinski C, Zimmer W: First isolation of an isoprene synthase gene from poplar and successful expression of the gene in Escherichia coli. Planta 2001, 213:483-487.

30. Lücker J, Bowen P, Bohlmann J: Vitis vinifera terpenoid cyclases. Phytochemistry 2004, 65:2649-2659.

31. Martin DM, Bohlmann J: Identification of Vitis vinifera (-)-a-terpineol synthase by in silico screening of full-length cDNA ESTs and functional characterization of recombinant terpene synthase. Phytochemistry 2004, 65:1223-1229.

32. Martin DM, Toub O, Chiang A, Lo BC, Ohse S, Lund ST, Bohlmann J: The bouquet of grapevine (Vitis vinifera L. cv. Cabernet Sauvignon) flowers arises from the biosynthesis of sesquiterpene volatiles in pollen grains. Proc Natl Acad Sci USA 2009, 106:7245-7250.

33. Bohlmann J, Meyer-Gauen G, Croteau R: Plant terpenoid synthases: molecular biology and phylogenetic analysis. Proc Natl Acad Sci USA 1998, 95:4126-4133.

34. Tholl D: Terpene synthases and the regulation, diversity and biological roles of terpene metabolism. Curr Opin Plant Biol 2006, 9:297-304.

35. Howe KL, Chothia T, Durbin R: GAZE: a generic framework for the integration of gene-prediction data by dynamic programming. Genome Res 2002, 12:1418-1427.

36. Velasco R, Zharkikh A, Troggio M, Cartwright DA, Cestaro A, Pruss D, Pindo M, Fitzgerald LM, Vezzulli S, Reid J, Malacarne G, lliev D, Coppola G, Wardell B, Micheletti D, Macalma T, Facci M, Mitchell JT, Perazzolli $M$, Eldredge G, Gatto P, Oyzerski R, Moretto M, Gutin N, Stefanini M, Chen Y, Segala C, Davenport C, Dematte L, Mraz A, Battilana J, Stormo K, Costa F, Tao Q, Si-Ammour A, Harkins T, Lackey A, Perbost C, Taillon B, Stella A Solovyev V, Fawcett JA, Sterck L, Vandepoele K, Grando SM, Toppo S, Moser C, Lanchbury J, Bogden R, Skolnick M, Sgaramella V, Bhatnagar SK, Fontana P, Gutin A, Van de Peer Y, Salamini F, Viola R: A high quality draft consensus sequence of the genome of a heterozygous grapevine variety. PLOS ONE 2007, 2:e3107.

37. Dudareva N, Martin D, Kish CM, Kolosova N, Gorenstein N, Faldt J, Miller B, Bohlmann J: (E)- $\beta$-Ocimene and myrcene synthase genes of floral scent biosynthesis in snapdragon: function and expression of three terpene synthase genes of a new terpene synthase subfamily. Plant Cell 2003, 15:1227-1241.
38. Keeling Cl, Dullat HK, Yuen M, Ralph SG, Jancsik S, Bohlmann J: Identification and functional characterization of monofunctional entcopalyl diphosphate and ent-kaurene synthases in white spruce reveal different patterns for diterpene synthase evolution for primary and secondary metabolism in gymnosperms. Plant Physiol 2010, 152:1197-1208.

39. Michelmore RW, Meyers BC: Clusters of resistance genes in plants evolve by divergent selection and a birth-and-death process. Genome Res 1998, 8:1113-1130.

40. Yang S, Feng Z, Zhang X, Jiang K, Jin X, Hang Y, Chen JQ, Tian D: Genomewide investigation on the genetic variations of rice disease resistance genes. Plant Mol Biol 2006, 62:181-193.

41. Xu S, Clark T, Zheng H, Vang S, Li R, Wong GK, Wang J, Zheng X: Gene conversion in the rice genome. BMC Genomics 2008, 9:93.

42. Fiston-Lavier AS, Anxolabehere D, Quesneville $\mathrm{H}$ : A model of segmental duplication formation in Drosophila melanogaster. Genome Res 2007, 17:1458-1470.

43. Hamberger B, Hall D, Yuen M, Oddy C, Hamberger B, Keeling Cl, Ritland C, Ritland K, Bohlmann J: Targeted isolation, sequence assembly and characterization of two white spruce (Picea glauca) BAC clones for terpenoid synthase and cytochrome P450 genes involved in conifer defence reveal insights into a conifer genome. BMC Plant Biol 2009, 9:106.

44. Trapp SC, Croteau RB: Genomic organization of plant terpene synthases and molecular evolutionary implications. Genetics 2001, 158:811-832.

45. Bateman A, Coin L, Durbin R, Finn RD, Hollich V, Griffiths-Jones S, Khanna A Marshall M, Moxon S, Sonnhammer EL, Studholme DJ, Yeats C, Eddy SR: The Pfam protein families database. Nucleic Acids Res 2004, 32:D138-41.

46. Starks CM, Back K, Chappell J, Noel JP: Structural basis for cyclic terpene biosynthesis by tobacco 5-epi-aristolochene synthase. Science 1997, 277:1815-1820.

47. Williams DC, McGarvey DJ, Katahira EJ, Croteau R: Truncation of limonene synthase preprotein provides a fully active 'pseudomature' form of this monoterpene cyclase and reveals the function of the amino-terminal arginine pair. Biochemistry 1998, 37:12213-12220.

48. Hyatt DC, Youn B, Zhao Y, Santhamma B, Coates RM, Croteau RB, Kang C: Structure of limonene synthase, a simple model for terpenoid cyclase catalysis. Proc Natl Acad Sci USA 2007, 104:5360-5365.

49. Rynkiewicz MJ, Cane DE, Christianson DW: Structure of trichodiene synthase from Fusarium sporotrichioides provides mechanistic inferences on the terpene cyclization cascade. Proc Natl Acad Sci USA 2001, 98:13543-13548.

50. Whittington DA, Wise ML, Urbansky M, Coates RM, Croteau RB, Christianson DW: Bornyl diphosphate synthase: structure and strategy for carbocation manipulation by a terpenoid cyclase. Proc Natl Acad Sci USA 2002, 99:15375-15380.

51. Prisic $S, X u J$, Coates RM, Peters RJ: Probing the role of the DXDD motif in Class II diterpene cyclases. Chembiochem 2007, 8:869-874.

52. Christianson DW: Structural biology and chemistry of the terpenoid cyclases. Chem Rev 2006, 106:3412-3442.

53. Degenhardt J, Kollner TG, Gershenzon J: Monoterpene and sesquiterpene synthases and the origin of terpene skeletal diversity in plants. Phytochemistry 2009, 70:1621-1637.

54. Sallaud C, Rontein D, Onillon S, Jabes F, Duffe P, Giacalone C, Thoraval S, Escoffier C, Herbette G, Leonhardt N, Causse M, Tissier A: A novel pathway for sesquiterpene biosynthesis from Z,Z-farnesyl pyrophosphate in the wild tomato Solanum habrochaites. Plant Cell 2009, 21:301-317.

55. Schilmiller AL, Schauvinhold I, Larson M, Xu R, Charbonneau AL, Schmidt A, Wilkerson C, Last RL, Pichersky E: Monoterpenes in the glandular trichomes of tomato are synthesized from a neryl diphosphate precursor rather than geranyl diphosphate. Proc Natl Acad Sci USA 2009, 106:10865-10870.

56. Martin DM, Faldt J, Bohlmann J: Functional characterization of nine Norway Spruce TPS genes and evolution of gymnosperm terpene synthases of the TPS-d subfamily. Plant Physiol 2004, 135:1908-1927.

57. Steele $\mathrm{CL}$, Crock J, Bohlmann J, Croteau R: Sesquiterpene synthases from grand fir (Abies grandis). Comparison of constitutive and wound-induced activities, and CDNA isolation, characterization, and bacterial expression of $\delta$-selinene synthase and $\gamma$-humulene synthase. J Biol Chem 1998, 273:2078-2089. 
58. Martin VJ, Pitera DJ, Withers ST, Newman JD, Keasling JD: Engineering a mevalonate pathway in Escherichia coli for production of terpenoids. Nat Biotechnol 2003, 21:796-802.

59. Morrone D, Xu M, Fulton DB, Determan MK, Peters RJ: Increasing complexity of a diterpene synthase reaction with a single residue switch. J Am Chem Soc 2008, 130:5400-5401.

60. Simionatto E, Porto C, Dalcol II, da Silva UF, Morel AF: Essential oil from >Zanthoxylum hyemale. Planta Med 2005, 71:759-763.

61. Yamaguchi S: Gibberellin metabolism and its regulation. Annu Rev Plant Biol 2008, 59:225-251.

62. Dudareva N, Cseke L, Blanc VM, Pichersky E: Evolution of floral scent in Clarkia: novel patterns of S-linalool synthase gene expression in the $C$. breweri flower. Plant Cell 1996, 8:1137-1148.

63. Luan F, Hampel D, Mosandl A, Wust M: Enantioselective analysis of free and glycosidically bound monoterpene polyols in Vitis vinifera L. cvs. Morio Muscat and Muscat Ottonel: evidence for an oxidative monoterpene metabolism in grapes. J Agric Food Chem 2004, 52:2036-2041.

64. Luan F, Mosandl A, Munch A, Wust M: Metabolism of geraniol in grape berry mesocarp of Vitis vinifera L. cv. Scheurebe: demonstration of stereoselective reduction, E/Z-isomerization, oxidation and glycosylation. Phytochemistry 2005, 66:295-303.

65. Tamborra P, Esti M: Authenticity markers in Aglianico, Uva di Troia, Negroamaro and Primitivo grapes. Anal Chim Acta 2010, 660:221-226.

66. Polaskova P, Herszage J, Ebeler SE: Wine flavor: chemistry in a glass. Chem Soc Rev 2008, 37:2478-2489.

67. Schiex T, Moisan A, Rouzé P: EuGène: An Eucaryotic Gene Finder that combines severalsources of evidence. In LNCS 2066 Edited by: Gascuel O, Sagot M-F 2001, 111-125

68. Florea L, Hartzell G, Zhang Z, Rubin GM, Miller W: A computer program for aligning a cDNA sequence with a genomic DNA sequence. Genome Res 1998, 8:967-974.

69. Rutherford K, Parkhill J, Crook J, Horsnell T, Rice P, Rajandream MA, Barrell B: Artemis: sequence visualization and annotation. Bioinformatics 2000 16:944-945.

70. Samson F, Brunaud V, Duchene S, De Oliveira Y, Caboche M, Lecharny A, Aubourg S: FLAGdb++: a database for the functional analysis of the Arabidopsis genome. Nucleic Acids Res 2004, 32:D347-50.

71. Emanuelsson O, Brunak S, von Heijne G, Nielsen H: Locating proteins in the cell using TargetP, SignalP and related tools. Nat Protoc 2007, 2:953-971.

72. Guindon S, Gascuel O: A simple, fast, and accurate algorithm to estimate large phylogenies by maximum likelihood. Syst Biol 2003, 52:696-704.

73. Reid KE, Olsson N, Schlosser J, Peng F, Lund ST: An optimized grapevine RNA isolation procedure and statistical determination of reference genes for real-time RT-PCR during berry development. BMC Plant Biol 2006, 6:27.

74. Zeng G: Sticky-end PCR: new method for subcloning. Biotechniques 1998, 25:206-208.

75. Keeling Cl, Weisshaar S, Lin RP, Bohlmann J: Functional plasticity of paralogous diterpene synthases involved in conifer defense. Proc Natl Acad Sci USA 2008, 105:1085-1090.

76. O'Maille PE, Chappell J, Noel JP: A single-vial analytical and quantitative gas chromatography-mass spectrometry assay for terpene synthases. Anal Biochem 2004, 335:210-217.

77. Adams RP: Carol Stream, Illinois: Allured Publishing Corporation; 2007.

78. Joulain D, König WA: Hamburg: E. B. Verlag; 1998.

doi:10.1186/1471-2229-10-226

Cite this article as: Martin et al:: Functional Annotation, Genome Organization and Phylogeny of the Grapevine (Vitis vinifera) Terpene Synthase Gene Family Based on Genome Assembly, FLcDNA Cloning, and Enzyme Assays. BMC Plant Biology 2010 10:226.

\section{Submit your next manuscript to BioMed Central and take full advantage of:}

- Convenient online submission

- Thorough peer review

- No space constraints or color figure charges

- Immediate publication on acceptance

- Inclusion in PubMed, CAS, Scopus and Google Scholar

- Research which is freely available for redistribution

Submit your manuscript at www.biomedcentral.com/submit
Biomed Central 